\section{Estudo \\ CoDebate}

em Cestã⿻

Plamejamento
Revista Estudo \& Debate, Lajeado, v. 24, n. 2, 2017. ISSN 1983-036X

DOI: http://dx.doi.org/10.22410/issn.1983-036X.v24i2a2017.1345

\title{
MANIFESTAÇÓES PATOLÓGICAS EM CASAS POPULARES: UMA ANÁLISE DE CUSTO
}

\author{
Leandro Galli Alves ${ }^{1}$, Victor Merchid Thomé2, Joice Paiva Tosta ${ }^{3}$
}

\begin{abstract}
Resumo: $\mathrm{O}$ crescimento desordenado dos centros urbanos associado a um aumento populacional registrado nas últimas décadas, culminou em um problema social no país: o déficit habitacional. Neste contexto, a iniciativa pública tem buscado desde 2009, com o início do programa Minha Casa Minha Vida do Governo Federal, implantar empreendimentos e conjuntos habitacionais voltados para as classes de menor poder aquisitivo, a fim de reduzir o problema habitacional do país. Entretanto relatos da literatura apontam que devido à precária gestão e fiscalização destes empreendimentos manifestaçôes patológicas têm sido detectadas precocemente nos conjuntos habitacionais de cunho popular. Diante desta problemática o presente estudo possui o objetivo de verificar a ocorrência de manifestaçóes patológicas em residências de interesse social para estimar o custo necessário para saná-las. Para isso, a metodologia utilizada foi um estudo de caso, promovido através de vistorias in loco em 15\% das residências inseridas em um conjunto habitacional popular de 179 unidades no município da Serra-ES, visando realizar levantamentos quantitativos das manifestaçôes patológicas presentes nesta amostra. Através da análise dos dados obtidos, verificou-se nos resultados que diversos elementos construtivos da amostra estudada (como cobertura, revestimento e esquadrias) possuem problemas construtivos que, consequentemente, geram manifestaçóes patológicas. Para estimar o custo de recuperação e readequação dos elementos alvo desta pesquisa foram realizadas consultas aos índices da construção civil SINAPI e IOPES, de forma elaborar um orçamento de obra. Diante da ampla ocorrência de manifestaçóes patológicas observadas no estudo de caso e do custo incorrido para correçáo das mesmas, os autores sugerem que novas pesquisas na área fazem-se necessárias de forma a propor melhorias em projetos e nos programas de qualidade utilizados na construção de moradias populares.
\end{abstract}

Palavras-chave: moradias populares, manifestações patológicas, índices da construção civil, custos.

\section{PATHOLOGICAL MANIFESTATIONS IN POPULAR HOUSING: AN A COST ANALISYS}

\begin{abstract}
The uncontrolled growth of urban centers associated with an increase in population in the last decades, culminating in a major social problem in the country's: housing deficit. In this context, the public initiative has sought since 2009, with the beginning of the Minha Casa Minha Vida program of the Federal Government,
\end{abstract}

1 Graduando em Engenharia Civil pela instituição FAESA Centro Universitário. In memoriam.

2 Engenheiro Civil pela instituição FAESA Centro Universitário.

3 Professora MSc. da instituição FAESA Centro Universitário. 
to implement projects and housing projects aimed at the lower income classes, in order to reduce the housing problem in the country. However literature reports indicate that due to lack of precarious management and surveillance of these pathological manifestations developments have been detected early in the projects of popular character. Faced with this problem the present study has the objective to verify the occurrence of pathological manifestations in homes of social interest in order to estimate the cost required to solve them. For this, the methodology used was a case study, sponsored by inspections on site in $15 \%$ of the inserted homes in a popular housing complex of 179 units in the city of Serra-ES, aiming to perform quantitative surveys of pathological manifestations present in this sample. Through data analysis, it was found in the results that different construction elements of the sample, as cover, coating, window frames, have both constructive problems like pathological manifestations. To estimate the cost of recovery and readjustment of the target elements of this research were conducted consultations with indexes construction SINAPI and IOPES in order to draw up a work budget. In view of the widespread occurrence of pathological manifestations observed in the case study and the cost incurred to correct them, the authors suggest that new research in the area is necessary in order to propose improvements in projects and quality programs used in the construction of popular housing

Keywords: Popular housing. Pathological manifestations. Construction industry indexes. Costs.

\section{INTRODUÇÃO}

O crescimento dos centros urbanos é um processo histórico construído a partir de fatores políticos, econômicos, sociais, entre outros. De acordo com Holz e Monteiro (2008) no início do século $\mathrm{XX}$ as cidades atraíram grande parte da população devido à rápida industrialização. Porém, a formação de áreas urbanas irregulares e ilegais deu-se devido à falta de políticas habitacionais que impedissem tal processo.

Assim, o histórico de ocupação de cidades brasileiras é marcado pelo crescimento desordenado, falta de planejamento, de gestáo e de fiscalizaçáo das construçôes, resultando em uma perda da qualidade de vida dos seus habitantes e usuários ao longo dos anos, principalmente para a parcela da populaçáo que possui menor poder aquisitivo (SPOSITO, 1991).

Tal cenário culminou em um problema social: o déficit habitacional. De acordo com um estudo anual acerca do setor habitacional no país e a evoluçáo de seus indicadores, considerando a falta ou inadequação do estoque urbano de moradias no Brasil, elaborado pela Fundação João Pinheiro (2013) e desenvolvido em parceria com o Ministério das Cidades, Banco Interamericano de Desenvolvimento (BID) e Programa das Naçóes Unidas para o Desenvolvimento (PNUD), por meio do Programa Habitar/Brasil/BID, estimou-se que até o ano de 2010, havia um déficit habitacional de 6 milhóes e 940 mil unidades no país.

Cabe destacar que, o déficit habitacional no Brasil não é um tema novo na pauta de preocupaçôes da época atual, a questáo habitacional encontra-se presente desde o final do século XIX, estendendo-se com maior preocupação, no decorrer do século XX, acompanhando o processo de desenvolvimento urbano (SPOSITO, 1991). A fim de diminuir esta problemática, o Governo Federal Brasileiro, junto com Estados e municípios, passaram a implementar projetos para a construção de moradias populares em larga escala. Contudo, tais programas possuem o desafio de construir unidades habitacionais a um menor custo final. Infelizmente, tal fato tem refletido na proliferação de moradias de baixa qualidade construtiva (LIMA, 2005). 
Assim, Miranda e Correa (2013) discorrem sobre a importância de repensar sobre a qualidade das habitaçôes populares no país, atentando para que as exigências mínimas de desempenho para uma construção exigidas pela norma NBR 15.575 (2013) sejam atendidas, além de que os projetos sejam regulamentados nas normas técnicas de engenharia vigentes. Neste contexto Oliveira e Mitidieri Filho (2012), destacam que o setor construtivo tem sido marcado pelo desenvolvimento precoce, de manifestaçóes patológicas em sua estrutura, seja por falhas de projeto, execuçáo ou especificação incorreta de materiais, causando o comprometimento das condiçóes de segurança e habitabilidade, exigindo assim um elevado número de açóes de manutenção de forma a sanar tais manifestaçôes patológicas.

Voltando-se para o conceito de patologia na construçáo civil, esta pode ser definida como o estudo das falhas construtivas (INSITUTO BRASILEIRO DE AVALIAÇŌES E PERÍCIAS DE ENGENHARIA, 1998). De acordo com Rocha et al. (2006), tal ciência aborda os sintomas, mecanismos de ocorrência, causas e as origens dos defeitos que podem ocorrer nas construçôes. Assim, o estudo de manifestaçóes patológicas possibilita diagnosticar precocemente os problemas que ocorrem nas edificaçóes, sanar tais problemas, bem como evitar que os mesmos venham a se repetir no futuro (PINA, 2013).

De acordo com Duarte (2001), destaca-se que tais manifestaçóes patológicas podem originar-se devido a uma série de fatores, como: o envelhecimento natural da edificação, falhas de projeto, erros na execução, emprego de materiais inadequados, e falta de manutenção. Todos estes elementos resultam no desenvolvimento de anomalias no sistema construtivo, que consequentemente afetam o seu desempenho. Contudo, para deteç̧ão de manifestaçôes patológicas, faz-se necessário a realização de uma vistoria no local de interesse para determinaçấo da existência, gravidade e área de extensão das manifestaçóes patológicas.

Considerando os problemas que ocorrem durante a concepção, execuçáo e a finalização de uma construção, e que consequentemente colaboram para o surgimento de anomalias nas edificaçóes, compreende-se a grande relevância de propor um estudo, cujo objetivo geral é identificar e analisar os custos unitários e orçamento necessários para reparar as possíveis manifestaçóes patológicas comumente encontradas em um conjunto de moradias populares, localizado no município de Serra-ES.

Diante desse contexto, essa pesquisa busca responder a seguinte questáo norteadora: Quais os custos necessários para reparar as manifestaçóes patológicas encontradas em um conjunto de moradias populares localizado na Serra-ES?

Desta forma, buscou-se verificar a existência de manifestaçôes patológicas nas unidades pesquisadas. Foram feitas pesquisas dos índices de referências da construção civil, dos custos das técnicas necessárias para a reparação de cada manifestação patológica e, por fim, com base nos índices pesquisados, elaborou-se composiçóes de menor custo, para sanar as manifestaçóes patológicas mais significativas. Tal pesquisa justifica-se pela importância de promover e incentivar mudanças comportamentais no meio técnico (projetistas, construtoras, etc.) para melhoria de gestâo e qualidade de produçấo de conjuntos de moradias populares. 


\section{REFERENCIAL TEÓRICO}

\subsection{Patologia na construção civil}

De acordo com França et al. (2011), a Patologia é o ramo da Engenharia Civil que estuda os sintomas, os mecanismos de ocorrência, as causas e as origens das anomalias que podem ocorrer nas construçóes ao longo da sua vida útil, causando uma depreciação no desempenho do empreendimento.

Esta ciência tem a capacidade de obter uma gama de dados a partir da análise dos problemas diagnosticados, visando contribuir no controle de qualidade no processo de construção de novas edificações, através de identificações das principais falhas que originam as manifestaçóes patológicas e aplicando estes conhecimentos adquiridos, na resolução de futuros problemas (ROCHA et al., 2006). Vale destacar que, normalmente, os fenômenos patológicos apresentam características externas próprias, possibilitando assim, deduzir sua natureza, a origem e os mecanismos associados a tal manifestação a partir destes sintomas (HELENE, 1992).

As manifestações patológicas em edificações podem se originar nas fases de planejamento, projeto, fabricação de materiais e/ou componentes, bem como durante a execução ou uso pelos usuários (RIPPER; MOREIRA SOUZA, 1998). O fator determinante para a ocorrência de anomalias em cada uma destas etapas é o nível de controle e planejamento aplicado na realização destes processos. Este controle deve ser maior principalmente na fase de projeto, uma vez que segundo Gradinski (2004), no Brasil foi percebido que 40\% das manifestaçóes patológicas rotineiramente constatadas em perícias poderiam ter sido evitadas na fase de projeto. A falta de detalhamento necessário foi um dos principais erros constatados e que dificilmente são consertados durante a execução.

Tendo em vista os problemas construtivos e patológicos que estão cada vez mais frequentes nas construçóes, bem como, em uma forma de garantir a qualidade construtiva dos empreendimentos de obra civil, a Associação Brasileira de Normas Técnicas (ABNT) instituiu no ano de 2013 a NBR no 15.575 - Norma de Desempenho de Edificaçóes Habitacionais, que instituiu exigências de conforto e segurança em imóveis residenciais de todos os portes (CBIC, 2013).

A norma em voga, é dividida em 6 (seis) partes, sendo estas, uma de requisitos gerais da obra e as demais referem-se aos sistemas que compóem o imóvel, aqui supracitados. E para cada uma dessas partes, a Norma estabelece padróes objetivos de qualidade (CAU/BR, 2013). De forma, geral a norma prevê diversas situaçóes de risco para o imóvel, fornecendo não só as medidas, mas as instruçóes necessárias para mesurar a segurança dos sistemas. Portanto, trata-se de um documento de elevado nível técnico, cujo objetivo e orientar os envolvidos em uma obra, sejam eles os fabricantes, projetivas e os construtores.

Tal norma, possibilitou a associação da qualidade dos produtos ao resultado que eles atribuem ao consumidor, por meio de instruçóes claras e objetivas de como avaliar esse contexto. Contudo, a NBR 15.575 afirma em seu texto normativo, que os níveis de segurança, conforto e resistência devem harmonizar cada um dos sistemas que compóem um imóvel: estrutura, pisos, vedações, coberturas e instalações (CBIC, 2013). 
É válido ressaltar que as normas versam acerca do resultado final de uma construção habitacional para estipular as condiçóes de uso e habitação que o mesmo deve assegurar, por isso é tấo relevante que tais habitaçôes atendam os parâmetros de qualidade e desempenho.

Voltando para o âmbito das manifestações patológicas, Pina (2013) relata que durante a fase de concepção da edificação, deve-se atentar para quaisquer anomalias existentes no estudo preliminar, no anteprojeto ou no projeto final de engenharia. Estes produtos são a base de todo o empreendimento, assim qualquer erro nessa fase irá, consequentemente, prejudicar o andamento das outras fases.

\subsection{Origens das manifestaçóes patológicas}

De acordo com Almeida (2008), os principais responsáveis pelo desenvolvimento de manifestações patológicas durante a fase de execução da obra são: falta de capacitação da mão de obra, a má execução do projeto, o uso de materiais com baixas qualidades, além de falhas na dosagem correta dos componentes empregados. Além dos erros supracitados, outros processos da fase de construção também podem gerar futuras manifestaçôes patológicas, como:

1. Falta de condiçóes locais de trabalho, tais como cuidados e motivaçáo;

2. Limitada capacitação profissional da mão de obra;

3. Deficiência no controle de qualidade de execução e/ou fiscalização;

4. Falta de prumo, de esquadro e de alinhamento dos elementos;

5. Desnivelamento de pisos e/ou falta de caimento em pisos molhados;

6. Argamassas de assentamento de revestimentos com espessuras diferentes;

7. Flechas e/ou rotaçôes excessivas;

8. A ausência de normatização de diversos materiais e procedimentos.

De acordo com Lima (2005), muitas manifestaçóes patológicas são originadas durante a fase de utilização da edificação, após a ocupação pelos usuários, em funçâo de diversos fatores, como: sobrecargas não previstas no projeto; alteraçóes estruturais indevidas em função das reformas; utilização de produtos agressivos na limpeza ou ainda derramamento acidentais de produtos agressivos, falta de manutençáo adequada, falta de inspeçóes periódicas.

Uma prática que constantemente gera manifestaçôes patológicas devido ao uso, é a limpeza inadequada da edificação, isto deve-se ao uso de equipamentos e produtos impróprios que tendem a afetar o desempenho da construçáo (ROCHA et al. 2006). Podese citar como exemplo de situações onde tal cenário é verificado as seguintes situações:

1. Limpeza da calha-Ao limpar esta área o usuário tende a despejar a sujeira no ralo, obstruindo o condutor, ocasionando o alagamento da laje e, consequentemente, infiltração;

2. Limpeza de entupimentos - $\mathrm{O}$ emprego de produtos como soda cáustica e água quente para sanar o entupimento, danifica a tubulaçáo de PVC, diminuindo sua vida útil; 
3. Instalação de antenas - Ao furar a laje impermeabilizada para instalar a antena, o usuário pode comprometer a estanqueidade da manta; e

4. Limpeza da fachada - A falta de manutenção e rejuntamento das fachadas pode resultar em infiltração e até desplacamento dos revestimentos.

As manifestaçóes patológicas mais comumente encontradas nas edificaçóes são: trincas, fissuras, rachaduras, degradação do concreto, manchas, descolamento de revestimentos em fachadas, infiltração, falhas de concretagem, eflorescência etc. De acordo Bernardo (apud PINA, 2013), observou registradas pelos usuários com maior frequência ocorriam nos componentes hidráulicos que as anomalias (FIGURA 1), seguido de trincas nas paredes e problemas de impermeabilização.

Figura 1 - Manifestaçóes Patológicas observadas nos edifícios

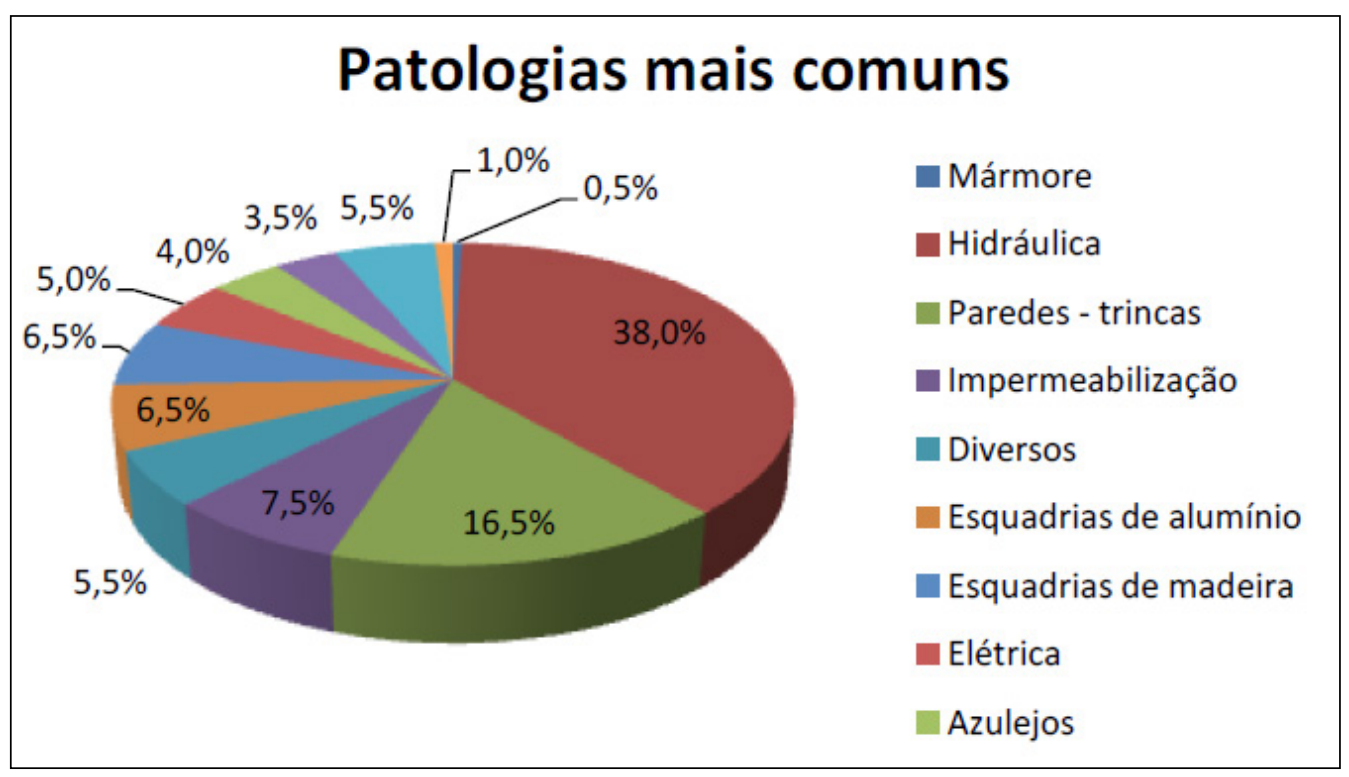

Fonte: Bernardo (apud PINA, 2013).

Cabe salientar que a ocorrência de manifestaçóes patológicas de qualquer natureza em uma edificação gera a necessidade de uma futura manutenção, reforma ou revitalização para sanar tal problema. Tais práticas são onerosas e causam prejuízo e desconforto tanto para as construtoras quanto para os usuários. Assim, é fundamental que profissionais, construtoras e usuários da área de construção venham a investir constantemente na prevenção destas anomalias, como forma de garantir a durabilidade, estabilidade, segurança, desempenho das edificaçôes, além de uma redução de custos tanto futuros quanto no decorrer da obra (LIMA, 2005).

Ripper e Moreira Souza (1998) descrevem que na prática, construtoras e profissionais, tendem a aguardar até o momento em que o desempenho da edificação estiver insatisfatório para buscarem soluçóes e tomarem as medidas adequadas. No entanto, a promoção de 
inspeçôes periódicas na edificação aumenta a possibilidade de diagnosticar e resolver o problema, além de reduzir os custos necessários para tal ação.

Desta forma, torna-se evidente a necessidade da manutenção periódica de uma edificação, já que este importante processo favorece a conservação e melhoria de desempenho das construçôes. Assim, é dever do construtor determinar a periodicidade e parâmetros de manutenção do empreendimento, bem como repassar estas informaçôes aos usuários através do manual de edificação (GRADISKI, 2004).

\subsection{Custos de manutençóes}

De acordo com Pujadas (2012), as principais características da manutenção associamse à recuperação e conservação dos edifícios. As reformas e modificaçóes dos sistemas não são consideradas como ações de manutenção. Assim, a manutenção deve ter início na etapa de concepção de projeto das edificaçóes no qual são estabelecidos procedimentos necessários à sua conservação e recuperação, bem como a capacidade de manutenibilidade.

Por outro lado, se a manutenção de elementos deficientes e as intervençóes preventivas necessárias ao longo da vida útil da edificação forem antevistos na etapa de projeto, os custos com manutençáo podem ser reduzidos, conforme demonstra a Lei de Sitter (ou Lei dos Cinco), ilustrada na FIGURA 2, que demonstra a evolução dos custos de manutenção, assimilados a uma progressão geométrica de razão 5 (HELENE, 2003).

Figura 2 - Representação da evolução dos custos em função da fase da vida da estrutura em que a intervenção é feita.

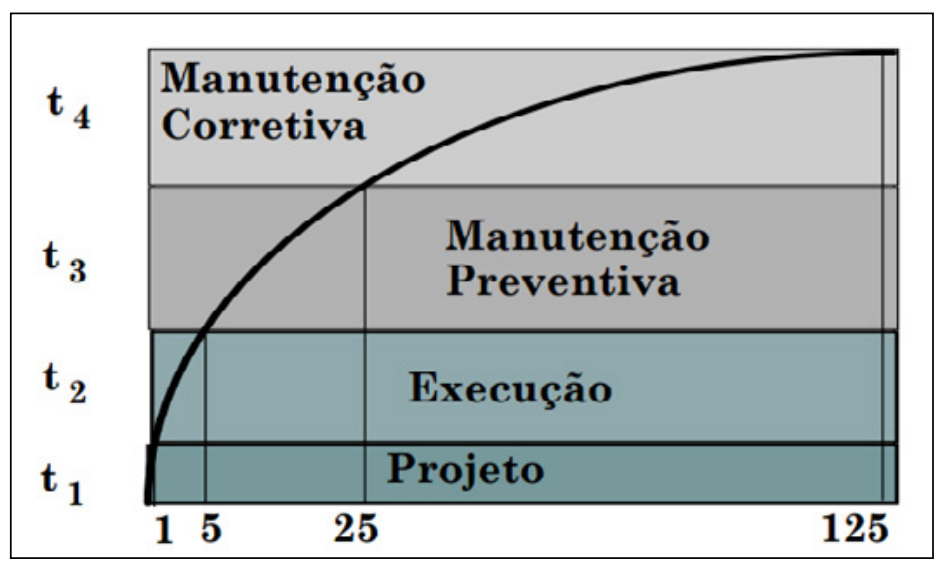

Fonte: Helene (2003).

Isto posto, reforça-se a importância do estudo em questáo como forma de promover e intensificar a fiscalização da qualidade construtiva, bem como da correta concepção dos projetos de edificações. 


\section{METODOLOGIA}

\subsection{Classificaçáo da pesquisa}

Para atingir os objetivos propostos neste estudo, elaborou-se uma metodologia em três etapas: levantamento bibliográfico, estudo de caso e elaboração de composiçôes de custo unitário. Primeiramente, iniciou-se o Levantamento Bibliográfico, a partir de consultas em artigos, livros, entrevistas e reportagens acerca do tema em questão, com o intuito de embasar o estudo e possibilitar maior esclarecimento acerca do assunto.

Após a conclusão da pesquisa bibliográfica, foi realizada um Estudo de Caso, por meio de uma visita de campo em um conjunto residencial popular localizado no município de Serra-ES a fim de realizar uma amostragem das manifestaçóes patológicas existentes em trinta unidades do referido condomínio. O estudo de caso foi promovido a partir dos dados obtidos na vistoria.

Gonsalves (2005) destaca que, no geral, o estudo de caso, ao realizar um exame minucioso de uma experiência, objetiva colaborar na tomada de decisóes sobre o problema estudado, indicando as possibilidades para a sua modificação.

A pesquisa em questão é de natureza quantitativa, visando mensurar a ocorrência e frequência de cada tipo de manifestação patológica através de dados precisos e confiáveis. Os dados obtidos foram tratados, organizados em tabelas e gráficos, com o objetivo de permitir majorar e listar as anomalias diagnosticadas.

Após os levantamentos supracitados foram desenvolvidas composiçóes de custos das manifestaçôes patológicas mais frequentes, com base em pesquisas de mercado e índices referenciais de preços da construção civil como: o Instituto de Obras Públicas do Estado do Espírito Santo (IOPES) e o Sistema Nacional de Pesquisa e Índices da Construção Civil (SINAPI), a fim de obter o custo necessário para restaurar e reconstruir (em alguns casos) os sistemas e elementos construtivos que possuem as anomalias examinadas.

\subsection{Universo, amostra e instrumento de coleta de dados}

Do universo total de 179 (cento e setenta e nove) casas de um conjunto residencial popular localizado no município de Serra-ES, a amostra analisada para esta pesquisa foi de 30 (trinta) casas (FIGURA 3). O empreendimento em questáo faz parte do Projeto Prioritário de Investimentos (PPI) de Novo Horizonte celebrado entre o Ministério das Cidades e o município de Serra, cujo objetivo é a implantação de ações necessárias para garantir a segurança, salubridade e a habitabilidade de comunidades em situaçáo de vulnerabilidade social, residente em áreas de risco ou ocupaçōes irregulares em áreas de preservação ambiental, através da habitação digna, saneamento e inclusão social (PMS, 2009). O empreendimento em questão foi entregue aos condôminos em duas etapas: a primeira etapa ( 57 unidades) foi entregue em 01/12/2014 e a segunda etapa (122 unidades) foi entregue em 02/06/2015. 
Figura 3 - Localização Geográfica do Condomínio de Unidades Habitacionais

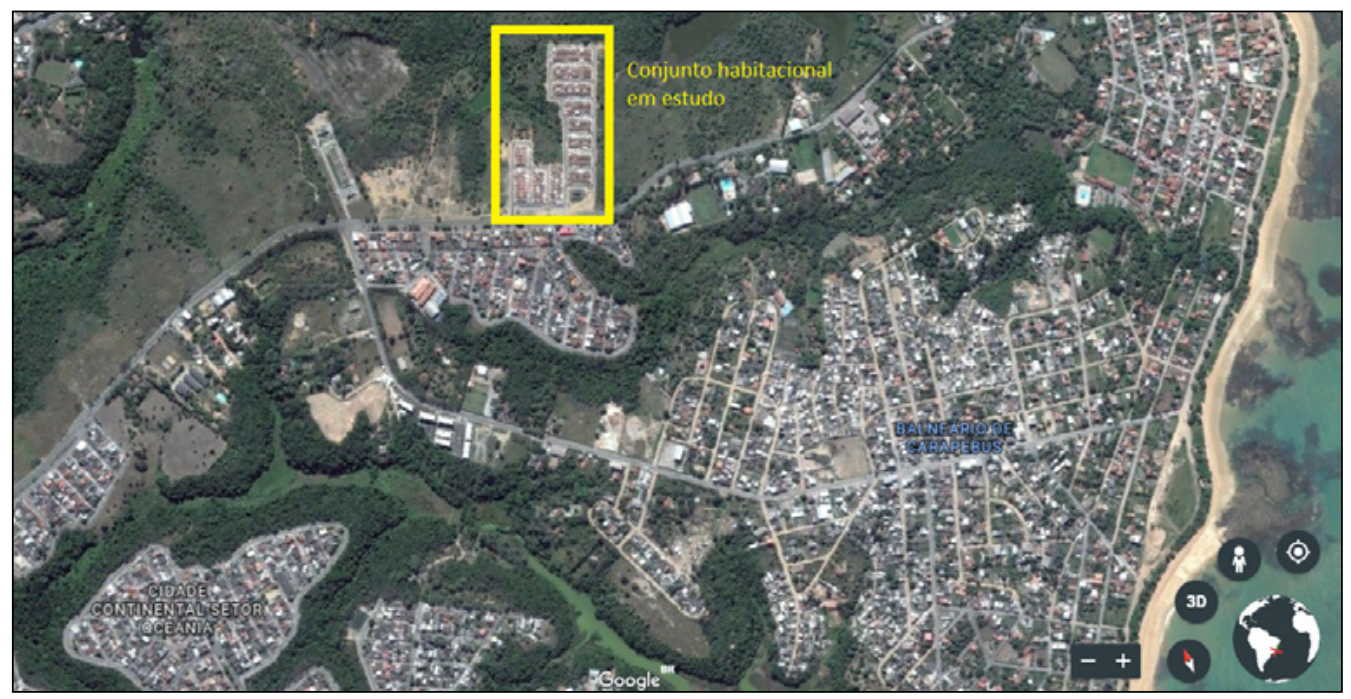

Fonte: Google Earth (2016).

Conforme escrito, o conjunto habitacional é formado por um universo de 179 unidades residenciais (FIGURA 4), que favoreceram, aproximadamente, 700 (setecentas) pessoas, cujo modelo construtivo possui as seguintes especificaçóes: alvenaria de elevação em bloco de concreto estrutural com área construída de aproximadamente 40 (quarenta) metros quadrados, subdivididos em dois quartos, sala, cozinha e banheiro. Implantadas em um terreno de 9 (nove) metros de largura por 14 (quatorze) metros de comprimento, totalizando uma área de 126 (cento e vinte e seis) metros quadrados. Todas as unidades são contempladas com esgotamento sanitário, abastecimento de água, além de ruas pavimentadas, calçadas padronizadas, drenagem pluvial, iluminação pública e sistema de aquecimento térmico do chuveiro à energia solar (PMS, 2009). 
Figura 4 - Conjunto Habitacional Bicanga

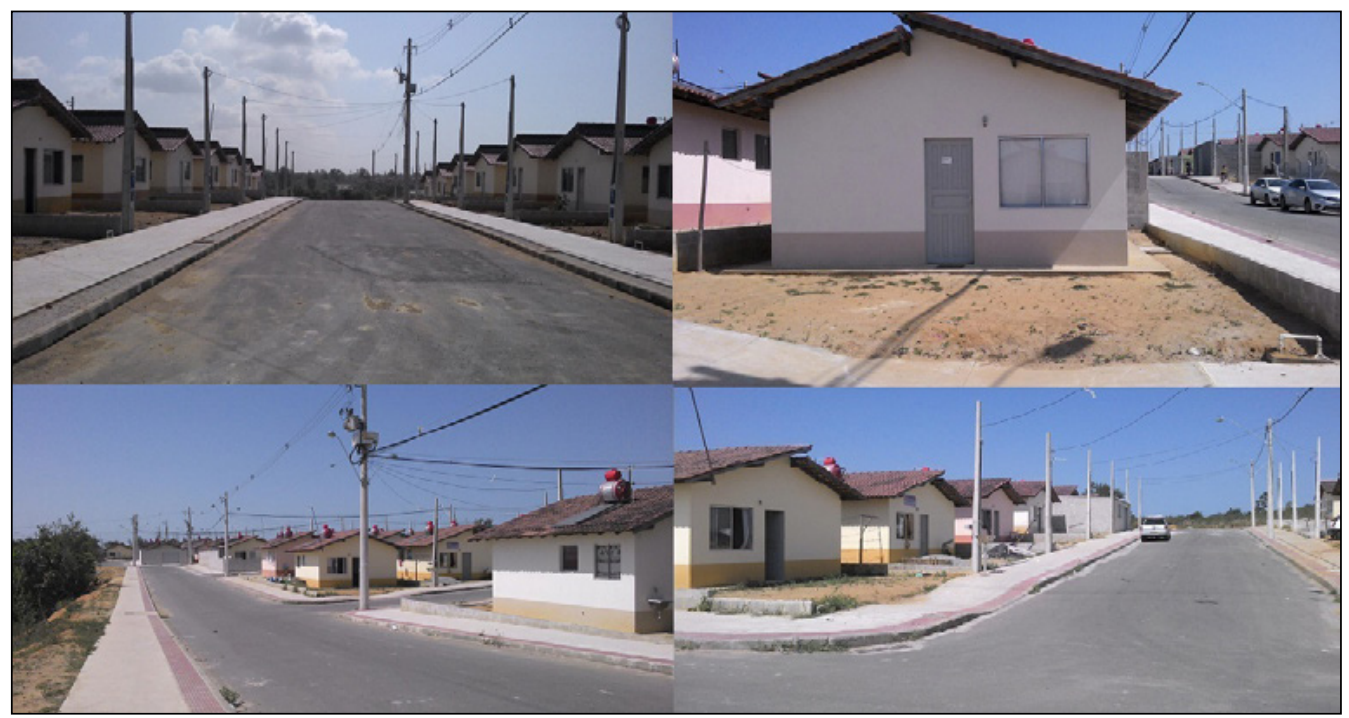

Fonte: Elaborado pelos autores.

Para obter dados acerca das manifestaçóes patológicas existentes nas unidades estudadas, foram vistoriadas 30 residências deste condomínio, de forma aleatória, em duas visitas de campo ocorridas nos dias 15/04/16 e 25/04/16, entre 8 h às $18 \mathrm{~h}$. Não foram vistoriadas as 179 unidades devido a dois fatores: alto índice de residências fechadas durante o período de vistoria e a falta de colaboração de muitos moradores, que se negaram a participar do estudo. Para nortear a obtenção de dados e facilitar a abordagem aos moradores, adaptou-se um check-list elaborado por Klimpel e Santos (2010), apresentado no Quadro 1. Durante as vistorias, realizou-se abordagens aos moradores do local, a fim de questionar sobre a possível existência de manifestaçóes patológicas em sua residência.

Quadro 1 - Check-list para Verificação de manifestações patológicas nas Unidades Habitacionais

\begin{tabular}{|c|c|c|}
\hline Sistema Construtivo & & \\
\hline \multicolumn{3}{|l|}{ Local / Cômodo } \\
\hline Manifestaçáo patológica & $\begin{array}{l}\text { Quantidade de unidades atingidas } \\
\text { (entre } 30 \text { unidades vistoriadas) }\end{array}$ & $\begin{array}{l}\text { Percentual (em relaçáo } \\
\text { ao total) }\end{array}$ \\
\hline \multicolumn{3}{|c|}{\begin{tabular}{|l|l} 
Alvenaria de elevaçáo (Paredes) & \\
\end{tabular}} \\
\hline \multicolumn{3}{|c|}{\begin{tabular}{|l|l|} 
Face externa da parede & \\
\end{tabular}} \\
\hline \multicolumn{3}{|l|}{ Lascamento } \\
\hline \multicolumn{3}{|l|}{ Falta de Prumo } \\
\hline \multicolumn{3}{|l|}{ Face interna da parede } \\
\hline \multicolumn{3}{|l|}{ Lascamento } \\
\hline Falta de Prumo & & \\
\hline
\end{tabular}




\begin{tabular}{|c|c|c|}
\hline Sistema Construtivo & & \\
\hline \multicolumn{3}{|l|}{ Local / Cômodo } \\
\hline Manifestaçáo patológica & $\begin{array}{l}\text { Quantidade de unidades atingidas } \\
\text { (entre } 30 \text { unidades vistoriadas) }\end{array}$ & $\begin{array}{c}\text { Percentual (em relaçáo } \\
\text { ao total) }\end{array}$ \\
\hline \multicolumn{3}{|l|}{ Revestimento interno } \\
\hline \multicolumn{3}{|l|}{ Esfarelado } \\
\hline \multicolumn{3}{|l|}{ Deficiência de Revestimento } \\
\hline \multicolumn{3}{|l|}{ Manchas de bolor e umidade } \\
\hline \multicolumn{3}{|l|}{ Revestimento externo } \\
\hline \multicolumn{3}{|l|}{ Esfarelado } \\
\hline \multicolumn{3}{|l|}{ Manchas de bolor e umidade } \\
\hline \multicolumn{3}{|l|}{ Falta de Revestimento } \\
\hline \multicolumn{3}{|l|}{ Piso } \\
\hline \multicolumn{3}{|l|}{ Sala } \\
\hline \multicolumn{3}{|l|}{ Presença de Umidade } \\
\hline \multicolumn{3}{|l|}{ Desnivelamento } \\
\hline \multicolumn{3}{|l|}{ Quartos } \\
\hline \multicolumn{3}{|l|}{ Presença de Umidade } \\
\hline \multicolumn{3}{|l|}{ Desnivelamento } \\
\hline \multicolumn{3}{|l|}{ Cozinha } \\
\hline \multicolumn{3}{|l|}{ Presença de Umidade } \\
\hline \multicolumn{3}{|l|}{ Desnivelamento } \\
\hline \multicolumn{3}{|l|}{ Banheiro } \\
\hline \multicolumn{3}{|l|}{ Presença de Umidade } \\
\hline \multicolumn{3}{|l|}{ Desnivelamento } \\
\hline \multicolumn{3}{|c|}{ Cobertura (Estrutura e telhamento) } \\
\hline \multicolumn{3}{|l|}{ Infestação por cupim } \\
\hline \multicolumn{3}{|l|}{ Fissuras e/ou Rachaduras } \\
\hline \multicolumn{3}{|l|}{ Lascamento } \\
\hline \multicolumn{3}{|l|}{ Estrutura sem Tratamento } \\
\hline \multicolumn{3}{|l|}{ Com manchas } \\
\hline \multicolumn{3}{|l|}{ Infiltração } \\
\hline Encaixei deficiente de peças & & \\
\hline Pintura interna & & \\
\hline Com bolhas & & \\
\hline Descascadas & & \\
\hline Pintura Externa & & \\
\hline Com bolhas & & \\
\hline Descascadas & & \\
\hline
\end{tabular}




\begin{tabular}{|c|c|c|}
\hline Sistema Construtivo & & \\
\hline \multicolumn{3}{|l|}{ Local / Cômodo } \\
\hline Manifestação patológica & $\begin{array}{l}\text { Quantidade de unidades atingidas } \\
\text { (entre } 30 \text { unidades vistoriadas) }\end{array}$ & $\begin{array}{c}\text { Percentual (em relaçáo } \\
\text { ao total) }\end{array}$ \\
\hline \multicolumn{3}{|l|}{ Esquadrias de madeira (Portas) } \\
\hline \multicolumn{3}{|l|}{ Má fixação } \\
\hline \multicolumn{3}{|l|}{ Apodrecimento } \\
\hline \multicolumn{3}{|l|}{ Esquadrias de aço (Janelas) } \\
\hline \multicolumn{3}{|l|}{ Má fixação } \\
\hline \multicolumn{3}{|l|}{ Instalaçóes Elétricas } \\
\hline \multicolumn{3}{|l|}{ Disjuntores desligam(caem) } \\
\hline \multicolumn{3}{|l|}{ Tomadas não funcionam } \\
\hline \multicolumn{3}{|l|}{ Instalaçóes Hidráulicas } \\
\hline \multicolumn{3}{|l|}{ Pouca pressão } \\
\hline Registros com problemas & & \\
\hline
\end{tabular}

Fonte: Elaborado pelos autores.

Nas 30 unidades em que os proprietários aceitaram participar da pesquisa e permitiam catalogar os problemas relatados, era promovido a aplicação do check-list supracitado. Em seguida, prosseguia-se para o interior das residências, com o devido consenso dos proprietários, para promoção de um registro fotográfico das manifestações patológicas relatadas e observadas no imóvel.

Com o intuito de preservar a identidade dos moradores participantes do estudo, não foi fotografado nenhum bem pessoal ou detalhe que possibilitaria identificar os proprietários das residências estudadas.

Assim, a partir dos relatos dos moradores e dos conhecimentos prévios, obteve-se os dados utilizados na pesquisa. Para verificar as manifestações patológicas mais recorrentes no objeto de estudo e selecionar os elementos que teriam destaque no estudo, promoveu-se uma análise quantitativa dos parâmetros obtidos em campo. Por fim, realizou-se consultas nos índices SINAPI e IOPES nas datas-bases de março/2016 e fevereiro/2016, respectivamente, com o intuito de estabelecer as composiçóes de custo unitário necessárias para sanar os problemas identificados, considerando a restauração e reconstrução (em alguns casos) dos elementos e sistemas com problemas.

\section{RESULTADOS}

Durante as vistorias foi realizado o preenchimento do check-list para todas as residências alvo desta pesquisa. Em seguida, com o auxílio do Software Microsoft Office Excel, quantificou-se o total identificado de manifestaçóes patológicas por sistema construtivo entre as 30 residências e destacou-se as manifestaçóes que tiveram maior percentual de incidência nos objetos do estudo (QUADRO 2). 
Quadro 2 - Total de manifestações patológicas identificadas na amostra em estudo

\begin{tabular}{|c|c|c|}
\hline Sistema Construtivo & & \\
\hline Local / Cômodo & & \\
\hline Manifestaçáo patológica & $\begin{array}{l}\text { Quantidade de unidades atingidas } \\
\text { (entre } 30 \text { unidades vistoriadas) }\end{array}$ & $\begin{array}{c}\text { Percentual (em relaçáo } \\
\text { ao total) }\end{array}$ \\
\hline \multicolumn{3}{|c|}{ Alvenaria de elevação (Paredes) } \\
\hline \multicolumn{3}{|l|}{ Face externa da parede } \\
\hline Lascamento & 12 & $40 \%$ \\
\hline Falta de Prumo & 0 & $0 \%$ \\
\hline \multicolumn{3}{|l|}{ Face interna da parede } \\
\hline Lascamento & 0 & $0 \%$ \\
\hline Falta de Prumo & 19 & $63 \%$ \\
\hline \multicolumn{3}{|l|}{ Revestimento interno } \\
\hline Esfarelado & 12 & $40 \%$ \\
\hline Deficiência de Revestimento & 22 & $73 \%$ \\
\hline Manchas de bolor e umidade & 11 & $37 \%$ \\
\hline \multicolumn{3}{|l|}{ Revestimento externo } \\
\hline Esfarelado & 15 & $50 \%$ \\
\hline Manchas de bolor e umidade & 15 & $50 \%$ \\
\hline Falta de Revestimento & 0 & $0 \%$ \\
\hline \multicolumn{3}{|l|}{ Piso } \\
\hline \multicolumn{3}{|l|}{ Sala } \\
\hline Presença de Umidade & 2 & $7 \%$ \\
\hline Desnivelamento & 6 & $20 \%$ \\
\hline \multicolumn{3}{|l|}{ Quartos } \\
\hline Presença de Umidade & 0 & $0 \%$ \\
\hline Desnivelamento & 4 & $13 \%$ \\
\hline \multicolumn{3}{|l|}{ Cozinha } \\
\hline Presença de Umidade & 0 & $0 \%$ \\
\hline Desnivelamento & 8 & $27 \%$ \\
\hline \multicolumn{3}{|l|}{ Banheiro } \\
\hline Presença de Umidade & 0 & $0 \%$ \\
\hline Desnivelamento & 20 & $67 \%$ \\
\hline \multicolumn{3}{|c|}{ Cobertura (Estrutura e telhamento) } \\
\hline Infestação por cupim & 15 & $50 \%$ \\
\hline Fissuras e/ou Rachaduras & 0 & $0 \%$ \\
\hline Lascamento & 0 & $0 \%$ \\
\hline Estrutura sem Tratamento & 30 & $100 \%$ \\
\hline Com manchas & 21 & $70 \%$ \\
\hline
\end{tabular}




\begin{tabular}{|c|c|c|}
\hline Sistema Construtivo & & \\
\hline \multicolumn{3}{|l|}{ Local / Cômodo } \\
\hline Manifestaçáo patológica & $\begin{array}{c}\text { Quantidade de unidades atingidas } \\
\text { (entre } 30 \text { unidades vistoriadas) }\end{array}$ & $\begin{array}{c}\text { Percentual (em relaçáo } \\
\text { ao total) }\end{array}$ \\
\hline Infiltração & 16 & $53 \%$ \\
\hline Encaixe deficiente de peças & 6 & $20 \%$ \\
\hline \multicolumn{3}{|l|}{ Pintura interna } \\
\hline Com bolhas & 0 & $0 \%$ \\
\hline Descascadas & 12 & $40 \%$ \\
\hline \multicolumn{3}{|l|}{ Pintura Externa } \\
\hline Com bolhas & 0 & \\
\hline Descascadas & 14 & $47 \%$ \\
\hline \multicolumn{3}{|c|}{ Esquadrias de madeira (Portas) } \\
\hline Má fixação & 14 & $47 \%$ \\
\hline Apodrecimento & 5 & $17 \%$ \\
\hline \multicolumn{3}{|l|}{ Esquadrias de aço (Janelas) } \\
\hline Má fixação & 10 & $33 \%$ \\
\hline \multicolumn{3}{|l|}{ Instalações Elétricas } \\
\hline Disjuntores desligam(caem) & 8 & $27 \%$ \\
\hline Tomadas não funcionam & 4 & $13 \%$ \\
\hline \multicolumn{3}{|l|}{ Instalaçóes Hidráulicas } \\
\hline Pouca pressão & 7 & $23 \%$ \\
\hline Registros com problemas & 5 & $17 \%$ \\
\hline
\end{tabular}

Fonte: Elaborado pelos autores.

Verificou-se que os três elementos construtivos que apresentavam maior índice de problemas foram: cobertura, revestimento argamassados interno e piso cerâmico do banheiro. Portanto, a seguir demonstram-se os problemas encontrados nestes três sistemas, bem como as composições de custos unitários elaboradas para restauração e tratamento dos sistemas construtivos em questão e os orçamentos para reconstituição destes sistemas em uma unidade habitacional.

\subsection{Cobertura}

No que diz respeito às coberturas, verificou-se dois problemas principais: estrutura de madeira aplicada sem tratamento seja contra cupim ou umidade (FIGURA 4-D), esta questão merece um destaque, uma vez que, foi o único problema constatado em todas as unidades vistoriadas. Cabe ressaltar que esse problema, além de levar ao desenvolvimento de diversas manifestações patológicas, também reduz a vida útil dos materiais. $\mathrm{O}$ segundo problema foi a má fixação da cobertura, em decorrência destas falhas, algumas residências estavam desenvolvendo manifestaçóes patológicas, como: infestação por cupins, eflorescência das telhas cerâmicas (FIGURA 5-A; B) e infiltração na cobertura. 
Figura 5 - Registro fotográfico dos problemas construtivos e manifestaçôes patológicas observados na cobertura. A - sugere-se o fenômeno de eflorescência ${ }^{4}$ nas telhas cerâmicas e estrutura sem tratamento. B - Destaque para o contato da estrutura de madeira com a alvenaria e eflorescencia da cobertura. C - Furos na cobertura cerâmica. D - Infiltração na alvenaria em função de falhas na cobertura

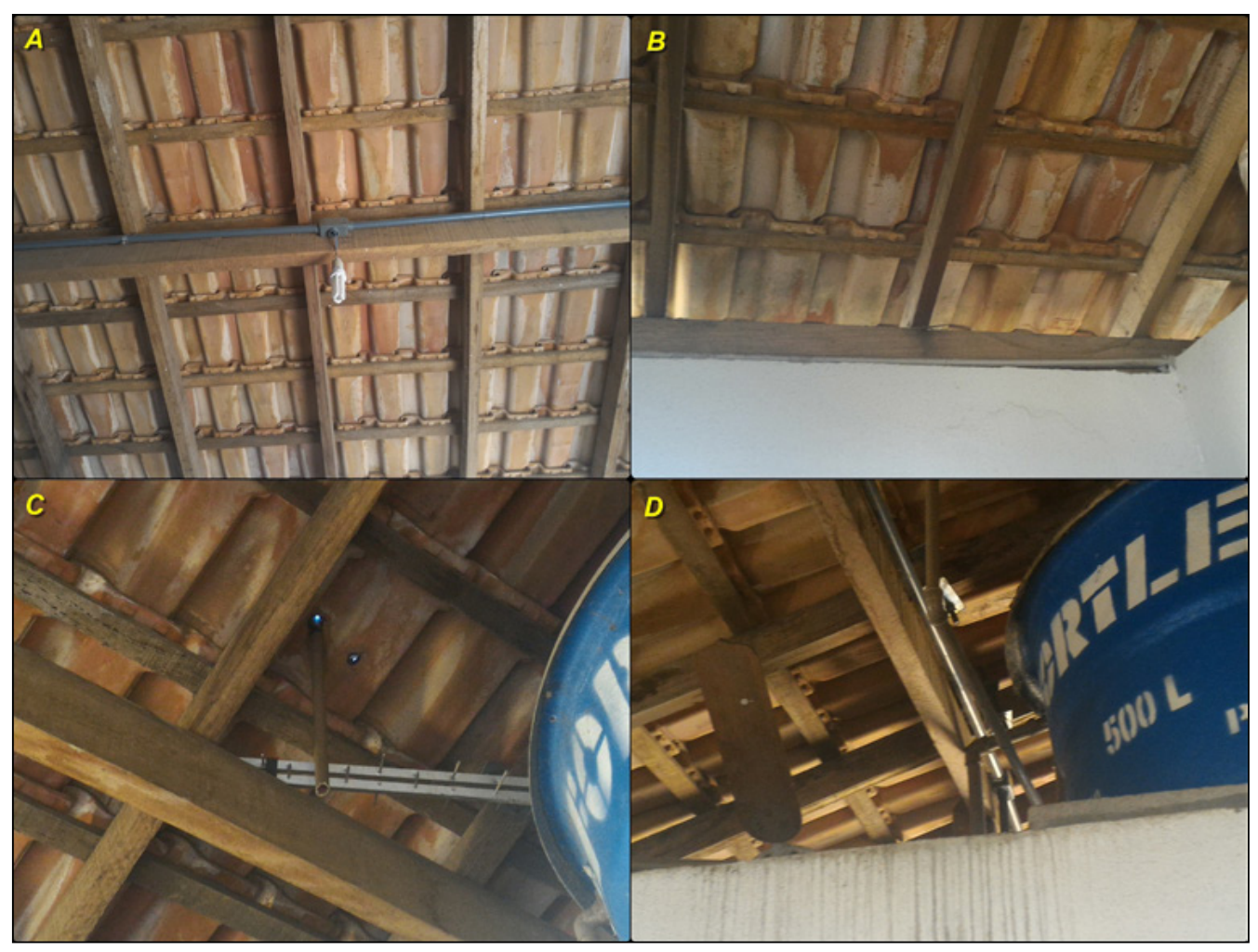

Fonte - Elaborado pelos autores

Considerando os problemas encontrados na cobertura fez-se levantamento junto ao SINAPI os serviços que seriam necessários promover nas residências, para sanar as manifestaçóes patológicas em questáo. Assim, para o elemento em questáo, requisita-se os seguintes serviços: remoçáo de rufo metálico, retirada de telhas de cerâmicas, limpeza/ preparo telhas cerâmicas $\mathrm{p} /$ pintura, impermeabilização de telhas cerâmicas utilizando pintura hidrofugante, imunização de madeiramento para cobertura utilizando cupinicida incolor, recolocação de rufo metálico, recolocação de telhas cerâmicas tipo plan, considerando reaproveitamento de material e revisão geral de telhados de telhas cerâmicas. Após o levantamento dos serviços necessário, elaborou-se a composição de custos unitários (QUADRO 3), para a restauração da cobertura.

4 Os autores sugerem o fenômeno de eflorescência pela aparência e condicionantes locais, porém ressaltam que ensaios laboratoriais são necessários para diagnóstico final do fenômeno. 
Quadro 3 - Composição de custos unitários para orçamento de restauração e tratamento da cobertura

\begin{tabular}{|c|c|c|c|c|c|c|c|}
\hline \multicolumn{8}{|c|}{ COMPOSIÇÃO UNITÁRIA PARA RESTAURAÇÃO DO SISTEMA DE COBERTURA COBERTURA } \\
\hline Fonte & Código & Descriçáo & Unidade & Índice & $\begin{array}{c}\text { Preço } \\
\text { Unitário }\end{array}$ & Custo & $\begin{array}{l}\text { SUB- } \\
\text { TOTAL }\end{array}$ \\
\hline \multirow[t]{4}{*}{ SINAPI } & 85414 & REMOCAO DE RUFO METALICO & M & & & & \\
\hline & & $\begin{array}{l}\text { SERVENTE COM ENCARGOS } \\
\text { COMPLEMENTARES }\end{array}$ & $\mathrm{H}$ & 0,20 & $\mathrm{R} \$ 11,97$ & $\mathrm{R} \$ 2,39$ & \\
\hline & & $\begin{array}{l}\text { TELHADISTA COM ENCARGOS } \\
\text { COMPLEMENTARES }\end{array}$ & $\mathrm{H}$ & 0,20 & $\mathrm{R} \$ 15,43$ & $\mathrm{R} \$ 3,09$ & \\
\hline & & & & & & & $\mathrm{R} \$ 5,48$ \\
\hline \multirow[t]{3}{*}{ SINAPI } & 72230 & $\begin{array}{l}\text { RETIRADA DE TELHAS DE } \\
\text { CERAMICAS OU DE VIDRO }\end{array}$ & $\mathrm{M}^{2}$ & & & & \\
\hline & & $\begin{array}{l}\text { SERVENTE COM ENCARGOS } \\
\text { COMPLEMENTARES }\end{array}$ & $\mathrm{H}$ & 0,5 & $\mathrm{R} \$ 11,97$ & $\mathrm{R} \$ 5,99$ & \\
\hline & & & & & & & R\$ 5,99 \\
\hline \multirow[t]{4}{*}{ SINAPI } & $73948 / 2$ & $\begin{array}{l}\text { LIMPEZA/PREPARO TELHAS } \\
\text { CERAMICAS P/PINTURA }\end{array}$ & $\mathrm{M}^{2}$ & & & & \\
\hline & & $\begin{array}{l}\text { SERVENTE COM ENCARGOS } \\
\text { COMPLEMENTARES }\end{array}$ & $\mathrm{H}$ & 0,5 & $\mathrm{R} \$ 11,97$ & $\mathrm{R} \$ 5,99$ & \\
\hline & & $\begin{array}{l}\text { ESCOVA DE ACO, COM CABO, }{ }^{*} 4 \mathrm{X} \\
15^{*} \text { FILEIRAS DE CERDAS }\end{array}$ & UND & 0,058 & $\mathrm{R} \$ 5,40$ & $\mathrm{R} \$ 0,31$ & \\
\hline & & & & & & & $\mathrm{R} \$ \mathbf{6 , 3 0}$ \\
\hline \multirow[t]{5}{*}{ SINAPI } & 73978/001 & HIDROFUGANTE & $\mathrm{M}^{2}$ & & & & \\
\hline & & $\begin{array}{l}\text { SERVENTE COM ENCARGOS } \\
\text { COMPLEMENTARES }\end{array}$ & $\mathrm{H}$ & 0,3 & $\mathrm{R} \$ 11,97$ & $\mathrm{R} \$ 3,59$ & \\
\hline & & $\begin{array}{l}\text { PINTOR COM ENCARGOS } \\
\text { COMPLEMENTARES }\end{array}$ & $\mathrm{H}$ & 0,3 & $\mathrm{R} \$ 17,39$ & $\mathrm{R} \$ 5,22$ & \\
\hline & & $\begin{array}{l}\text { HIDRORREPELENTE PARA } \\
\text { APLICAÇÃO EM TIJOLOS }\end{array}$ & $\mathrm{L}$ & 0,3 & $\mathrm{R} \$ 21,38$ & $\mathrm{R} \$ 6,41$ & \\
\hline & & & & & & & $\mathrm{R} \$ 15,22$ \\
\hline \multirow[t]{4}{*}{ SINAPI } & 55960 & $\begin{array}{l}\text { IMUNIZACAO DE MADEIRAMENTO } \\
\text { PARA COBERTURA UTILIZANDO } \\
\text { CUPINICIDA INCOLOR } \\
\end{array}$ & $\mathrm{M}^{2}$ & & & & \\
\hline & & $\begin{array}{l}\text { SERVENTE COM ENCARGOS } \\
\text { COMPLEMENTARES }\end{array}$ & $\mathrm{H}$ & 0,2 & $\mathrm{R} \$ 11,97$ & $\mathrm{R} \$ 2,39$ & \\
\hline & & $\begin{array}{l}\text { IMUNIZANTE PARA MADEIRA, } \\
\text { INCOLOR }\end{array}$ & $\mathrm{L}$ & 0,1 & $\mathrm{R} \$ 14,54$ & $\mathrm{R} \$ 1,45$ & \\
\hline & & & & & & & $\mathrm{R} \$ 3,85$ \\
\hline \multirow[t]{5}{*}{ SINAPI } & 40905 & $\begin{array}{l}\text { VERNIZ SINTETICO EM MADEIRA, } \\
\text { DUAS DEMAOS }\end{array}$ & $\mathrm{M}^{2}$ & & & & \\
\hline & & $\begin{array}{l}\text { PINTOR COM ENCARGOS } \\
\text { COMPLEMENTARES }\end{array}$ & $\mathrm{H}$ & 0,4 & $\mathrm{R} \$ 17,39$ & $\mathrm{R} \$ 6,96$ & \\
\hline & & $\begin{array}{l}\text { SERVENTE COM ENCARGOS } \\
\text { COMPLEMENTARES }\end{array}$ & $\mathrm{H}$ & 0,3 & $\mathrm{R} \$ 11,97$ & $\mathrm{R} \$ 3,59$ & \\
\hline & & $\begin{array}{l}\text { LIXA EM FOLHA PARA PAREDE } \\
\text { OU MADEIRA, NUMERO } 120 \text { (COR } \\
\text { VERMELHA) }\end{array}$ & UND & 1 & $\mathrm{R} \$ 0,74$ & $\mathrm{R} \$ 0,74$ & \\
\hline & & $\begin{array}{l}\text { SOLVENTE DILUENTE A BASE DE } \\
\text { AGUARRAS }\end{array}$ & $\mathrm{L}$ & 0,047 & $\mathrm{R} \$ 9,80$ & $\mathrm{R} \$ 0,46$ & \\
\hline
\end{tabular}




\begin{tabular}{|c|c|c|c|c|c|c|c|}
\hline \multicolumn{8}{|c|}{ COMPOSIÇÃO UNITÁRIA PARA RESTAURAÇÃO DO SISTEMA DE COBERTURA COBERTURA } \\
\hline \multirow[t]{3}{*}{ Fonte } & Código & Descriçáo & Unidade & Índice & \begin{tabular}{c|} 
Preço \\
Unitário
\end{tabular} & Custo & $\begin{array}{l}\text { SUB- } \\
\text { TOTAL }\end{array}$ \\
\hline & & $\begin{array}{l}\text { VERNIZ SINTETICO BRILHANTE } \\
\text { PARA MADEIRA TIPO COPAL, USO } \\
\text { INTERNO }\end{array}$ & $\mathrm{L}$ & 0,27 & $\mathrm{R} \$ 17,38$ & $\mathrm{R} \$ 4,69$ & \\
\hline & & & & & & & $\mathrm{R} \$ 16,44$ \\
\hline \multirow[t]{5}{*}{ SINAPI } & 860 & $\begin{array}{l}\text { RECOLOCAÇÃO DE RUFO } \\
\text { METALICO }\end{array}$ & M & & & & \\
\hline & & $\begin{array}{l}\text { SERVENTE COM ENCARGOS } \\
\text { COMPLEMENTARES }\end{array}$ & $\mathrm{H}$ & 0,2 & $\mathrm{R} \$ 11,97$ & $\mathrm{R} \$ 2,39$ & \\
\hline & & $\begin{array}{l}\text { TELHADISTA COM ENCARGOS } \\
\text { COMPLEMENTARES }\end{array}$ & $\mathrm{H}$ & 0,2 & $\mathrm{R} \$ 15,43$ & $\mathrm{R} \$ 3,09$ & \\
\hline & & $\begin{array}{l}\text { PREGO DE ACO POLIDO COM } \\
\text { CABECA } 18 \text { X } 27 \text { ( } 2 \text { 1/2 X 10) }\end{array}$ & KG & 0,1 & $\mathrm{R} \$ 8,65$ & $\mathrm{R} \$ 0,87$ & \\
\hline & & & & & & & $R \$ 6,35$ \\
\hline \multirow[t]{4}{*}{ SINAPI } & 72091 & $\begin{array}{l}\text { RECOLOCACAO DE } \\
\text { TELHAS CERAMICAS TIPO } \\
\text { PLAN, CONSIDERANDO } \\
\text { REAPROVEITAMENTO DE } \\
\text { MATERIAL } \\
\end{array}$ & $\mathrm{M}^{2}$ & & & & \\
\hline & & $\begin{array}{l}\text { SERVENTE COM ENCARGOS } \\
\text { COMPLEMENTARES } \\
\end{array}$ & $\mathrm{H}$ & 1,5 & $\mathrm{R} \$ 11,97$ & $\mathrm{R} \$ 17,96$ & \\
\hline & & $\begin{array}{l}\text { TELHADISTA COM ENCARGOS } \\
\text { COMPLEMENTARES }\end{array}$ & $\mathrm{H}$ & 0,75 & $\mathrm{R} \$ 15,43$ & $\mathrm{R} \$ 11,57$ & \\
\hline & & & & & & & $\mathrm{R} \$ 29,53$ \\
\hline \multirow[t]{4}{*}{ SINAPI } & 72101 & $\begin{array}{l}\text { REVISAO GERAL DE TELHADOS DE } \\
\text { TELHAS CERAMICAS }\end{array}$ & $\mathrm{M}^{2}$ & & & & \\
\hline & & $\begin{array}{l}\text { SERVENTE COM ENCARGOS } \\
\text { COMPLEMENTARES }\end{array}$ & $\mathrm{H}$ & 0,3 & $\mathrm{R} \$ 11,97$ & $\mathrm{R} \$ 3,59$ & \\
\hline & & $\begin{array}{l}\text { TELHADISTA COM ENCARGOS } \\
\text { COMPLEMENTARES }\end{array}$ & $\mathrm{H}$ & 0,1 & $\mathrm{R} \$ 15,43$ & $\mathrm{R} \$ 1,54$ & \\
\hline & & & & & & & $\mathrm{R} \$ 5,13$ \\
\hline
\end{tabular}

Fonte: Elaborado pelos autores.

O próximo passo foi a construção de um orçamento para averiguar os custos necessários para a restauração e tratamento de uma unidade habitacional. Para tal, foi necessário calcular a área de cobertura da residência. As medidas necessárias foram obtidas a partir do projeto arquitetônico das unidades habitacionais, disponibilizado pela Prefeitura municipal da Serra. Obtida a área do elemento e com os índices levantados junto ao SINAPI foi possível elaborar o orçamento (QUADRO 4), para restauração e tratamento da cobertura. 
Quadro 4 - Orçamento da restauração e tratamento da cobertura de uma unidade habitacional

\begin{tabular}{|c|c|c|c|c|c|c|}
\hline \multicolumn{7}{|c|}{ Restauraçáo e Tratamento de cobertura } \\
\hline Fonte & Código & Descrição do Serviço & Unidade & Quant. & $\begin{array}{c}\text { Preço } \\
\text { Unitário }\end{array}$ & Custo \\
\hline SINAPI & 85414 & REMOCAO DE RUFO METALICO & M & 6,39 & $\mathrm{R} \$ 5,48$ & $\mathrm{R} \$ 35,02$ \\
\hline SINAPI & 72230 & $\begin{array}{l}\text { RETIRADA DE TELHAS DE CERAMICAS } \\
\text { OU DE VIDRO }\end{array}$ & $\mathrm{M}^{2}$ & 53,87 & $\mathrm{R} \$ 5,99$ & $\mathrm{R} \$ 322,68$ \\
\hline SINAPI & $73948 / 2$ & $\begin{array}{l}\text { LIMPEZA/PREPARO TELHAS } \\
\text { CERAMICAS P/PINTURA }\end{array}$ & $\mathrm{M}^{2}$ & 53,87 & $\mathrm{R} \$ 6,30$ & $\mathrm{R} \$ 339,38$ \\
\hline SINAPI & $73978 / 001$ & $\begin{array}{l}\text { IMUNIZAÇÃO DE TELHAS } \\
\text { CERÂMICAS UTILIZANDO PINTURA } \\
\text { HIDROFUGANTE }\end{array}$ & $\mathrm{M}^{2}$ & 53,87 & $\mathrm{R} \$ 15,22$ & $\mathrm{R} \$ 819,90$ \\
\hline SINAPI & 55960 & $\begin{array}{l}\text { IMUNIZACAO DE MADEIRAMENTO } \\
\text { PARA COBERTURA UTILIZANDO } \\
\text { CUPINICIDA INCOLOR }\end{array}$ & $\mathrm{M}^{2}$ & 53,87 & $\mathrm{R} \$ 3,85$ & $\mathrm{R} \$ 207,40$ \\
\hline SINAPI & 40905 & $\begin{array}{l}\text { VERNIZ SINTETICO EM MADEIRA, } \\
\text { DUAS DEMAOS }\end{array}$ & $\mathrm{M}^{2}$ & 53,87 & $\mathrm{R} \$ 16,44$ & $\mathrm{R} \$ 885,62$ \\
\hline SINAPI & 860 & RECOLOCAÇÃO DE RUFO METALICO & M & 6,39 & $\mathrm{R} \$ 6,35$ & $\mathrm{R} \$ 40,58$ \\
\hline SINAPI & 72091 & $\begin{array}{l}\text { RECOLOCACAO DE } \\
\text { TELHAS CERAMICAS TIPO } \\
\text { PLAN, CONSIDERANDO } \\
\text { REAPROVEITAMENTO DE MATERIAL }\end{array}$ & $\mathrm{M}^{2}$ & 53,87 & $\mathrm{R} \$ 29,53$ & $\mathrm{R} \$ 1.590,78$ \\
\hline SINAPI & 72101 & $\begin{array}{l}\text { REVISAO GERAL DE TELHADOS DE } \\
\text { TELHAS CERAMICAS }\end{array}$ & $\mathrm{M}^{2}$ & 53,87 & $\mathrm{R} \$ 5,13$ & $\mathrm{R} \$ 276,35$ \\
\hline & & TOTAL DO ORÇAMENTO & & & & R\$ 4.517,71 \\
\hline
\end{tabular}

Fonte - Elaborado pelos autores

Assim, para corrigir apenas os problemas levantados na cobertura o proprietário de uma unidade habitacional terá que destinar um total de $\mathrm{R} \$ 4.517,71$. Este valor representa aproximadamente 3,7 vezes maior que o valor de rendimento nominal mensal domiciliar per capita da população brasileira residente em 2016, que foi de $\mathrm{R} \$ 1.226,00$ (IBGE, 2017).

\subsection{Alvenaria e revestimentos argamassados internos}

Quanto aos revestimentos argamassados foi observado que as unidades habitacionais vistoriadas foram executadas sem este elemento construtivo. Nas residências em questão, aplicou-se diretamente sobre a alvenaria, pintura texturizada, com o intuito de apenas recobrir os blocos. Tal fato provoca os seguintes problemas: falta de proteção da alvenaria contra infiltração, podendo levar a percolação da água para dentro dos blocos e futura deterioração do mesmo.

O fator acima possui o agravante de algumas residências já possuírem zonas de infiltração (FIGURA 6-A; B) desenvolvidas na alvenaria interna. O segundo fator são as imperfeições construtivas aparentes, como a falta de prumo (FIGURA 6-D; E; F), excesso de cordão de ligação entre os blocos, além do desconforto causado ao usuário por receber uma moradia com problemas notáveis de acabamento. 
Figura 6 - Registro fotográfico dos problemas construtivos e manifestaçôes patológicas observados na alvenaria interna. A e B - pontos de Infiltraçáo em decorrência de anomalias na cobertura. C - pintura texturizada sobre o bloco de alvenaria estrutural. D e E - excesso de cordão de argamassa na conexão dos blocos

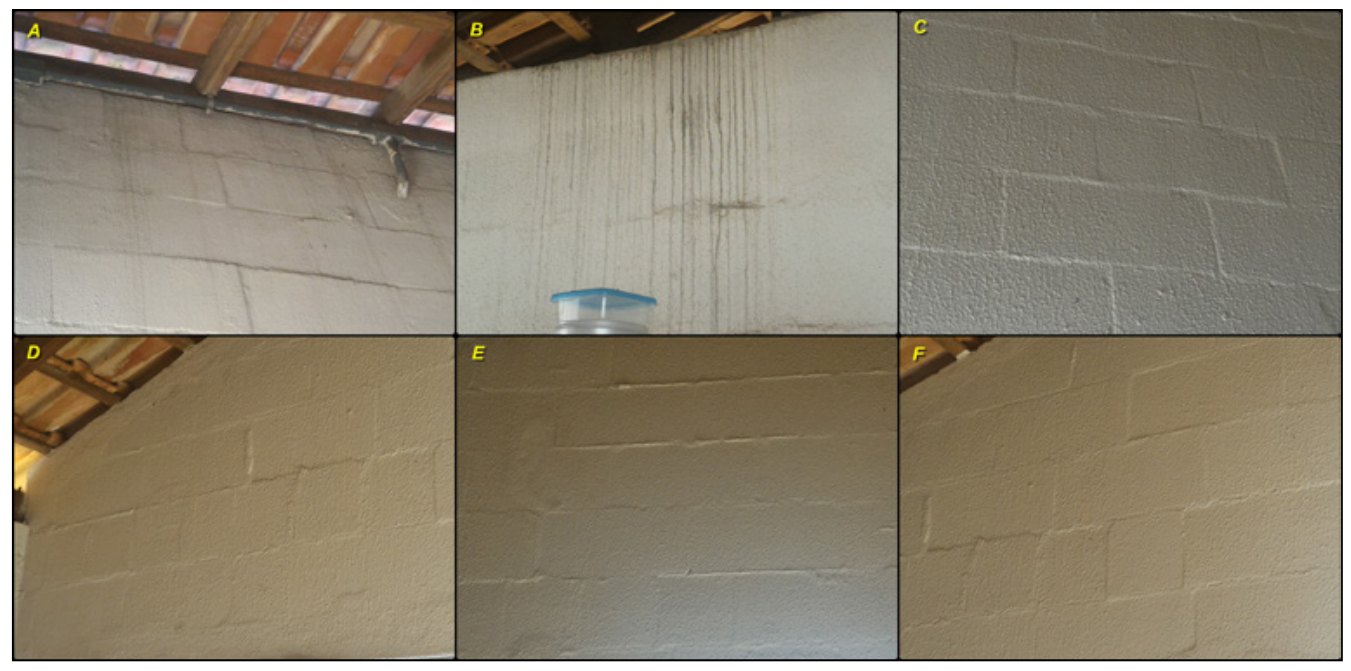

Fonte - Elaborado pelos autores

A solução proposta para sanar os problemas relatados é a remoção dos revestimentos existentes, limpeza das áreas com infiltração e a execução de um revestimento interno apropriado, composto de chapisco, emboço e reboco, seguida da aplicação de massa corrida para obter acabamento fino, para entáo aplicar a nova camada de pintura. Assim, foram promovidas consultas ao SINAPI com o intuito de verificar serviços, preços e índices de produtividade de forma elaborar a composição de custos unitários (QUADRO 5) para a recomposição dos revestimentos internos.

Quadro 5 - Composição de custos unitário para orçamento de recomposição dos revestimentos argamassados internos

\begin{tabular}{|l|c|l|c|c|c|c|c|}
\hline \multicolumn{6}{|c|}{ COMPOSIÇÃO UNITÁRIA PARA RESTAURAÇÃO DO SISTEMA DE REVESTIMENTOS ARGAMASSADOS } \\
\hline Fonte & Código & \multicolumn{1}{|c|}{ Descrição } & Unid. & Índice & $\begin{array}{c}\text { Preço } \\
\text { Unitário }\end{array}$ & Custo & $\begin{array}{c}\text { SUB- } \\
\text { TOTAL }\end{array}$ \\
\hline SINAPI & 72125 & $\begin{array}{l}\text { REMOÇÃO DE PINTURA PVA/ } \\
\text { ACRILICA }\end{array}$ & $\mathrm{M}^{2}$ & & & & \\
\hline & $\begin{array}{l}\text { SERVENTE COM ENCARGOS } \\
\text { COMPLEMENTARES }\end{array}$ & $\mathrm{H}$ & 0,5 & $\mathrm{R} \$ 11,97$ & $\mathrm{R} \$ 5,99$ & $\mathrm{R}$ \\
\hline & $\begin{array}{l}\text { LIXA EM FOLHA PARA PAREDE } \\
\text { OU MADEIRA, NUMERO 120 } \\
\text { (COR VERMELHA) }\end{array}$ & $\mathrm{UND}$ & 0,5 & $\mathrm{R} \$ 0,74$ & $\mathrm{R} 0,37$ & \\
\hline & & & & & & $\mathbf{R \$ \mathbf { 6 , 3 6 }}$ \\
\hline
\end{tabular}




\begin{tabular}{|c|c|c|c|c|c|c|c|}
\hline \multicolumn{8}{|c|}{ COMPOSIÇÃO UNITÁRIA PARA RESTAURAÇÁO DO SISTEMA DE REVESTIMENTOS ARGAMASSADOS } \\
\hline Fonte & Código & Descriçáo & Unid. & Índice & $\begin{array}{c}\text { Preço } \\
\text { Unitário }\end{array}$ & Custo & $\begin{array}{c}\text { SUB- } \\
\text { TOTAL }\end{array}$ \\
\hline \multirow[t]{5}{*}{ SINAPI } & 87868 & \begin{tabular}{l|} 
CHAPISCO APLICADO \\
SOMENTE EM ESTRUTURAS DE \\
CONCRETO EM ALVENARIAS \\
INTERNAS, COM COLHER DE \\
PEDREIRO. ARGAMASSA TRAÇO \\
1:3 COM PREPARO MANUAL. \\
\end{tabular} & $\mathrm{M}^{2}$ & & & & \\
\hline & & \multicolumn{2}{|c|}{$\begin{array}{l}\text { ARGAMASSA TRAÇO 1:3 (CIMENTO } \\
\text { E AREIA GROSSA) PARA CHAPISCO } \\
\text { CONVENCIONAL, PREPARO MANUAL. }\end{array}$} & 0 & $\mathrm{R} \$ 375,35$ & $\mathrm{R} \$ 1,58$ & \\
\hline & & $\begin{array}{l}\text { PEDREIRO COM ENCARGOS } \\
\text { COMPLEMENTARES }\end{array}$ & $\mathrm{H}$ & 0,09 & $\mathrm{R} \$ 17,39$ & $\mathrm{R} \$ 1,57$ & \\
\hline & & $\begin{array}{l}\text { SERVENTE COM ENCARGOS } \\
\text { COMPLEMENTARES }\end{array}$ & $\mathrm{H}$ & 0,01 & $\mathrm{R} \$ 11,97$ & $\mathrm{R} \$ 0,11$ & \\
\hline & & & & & & & $\mathbf{R} \$ 3,25$ \\
\hline \multirow[t]{6}{*}{ SINAPI } & 87368 & $\begin{array}{l}\text { ARGAMASSA TRAÇO 1:1,5:7,5 } \\
\text { (CIMENTO, CAL E AREIA } \\
\text { MÉDIA) PARA EMBOÇO/MASSA } \\
\text { ÚNICA/ASSENTAMENTO DE } \\
\text { ALVENARIA DE VEDAÇÃO, } \\
\text { PREPARO MANUAL. }\end{array}$ & $\mathrm{M}^{3}$ & & & & \\
\hline & & $\begin{array}{l}\text { SERVENTE COM ENCARGOS } \\
\text { COMPLEMENTARES }\end{array}$ & $\mathrm{H}$ & 11,5 & $\mathrm{R} \$ 11,97$ & $\mathrm{R} \$ 137,66$ & \\
\hline & & $\begin{array}{l}\text { AREIA MEDIA - POSTO JAZIDA/ } \\
\text { FORNECEDOR (SEM FRETE) }\end{array}$ & $\mathrm{M}^{3}$ & 1,28 & $\mathrm{R} \$ 30,00$ & $\mathrm{R} \$ 38,40$ & \\
\hline & & $\begin{array}{l}\text { CAL HIDRATADA CH-I PARA } \\
\text { ARGAMASSAS }\end{array}$ & KG & 0,60 & $\mathrm{R} \$ 153,50$ & $\mathrm{R} \$ 92,10$ & \\
\hline & & $\begin{array}{l}\text { CIMENTO PORTLAND } \\
\text { COMPOSTO CP II-32 }\end{array}$ & KG & 0,47 & $\mathrm{R} \$ 196,14$ & $\mathrm{R} \$ 92,19$ & \\
\hline & & & & & & & $\mathrm{R} \$ 360,34$ \\
\hline \multirow[t]{5}{*}{ SINAPI } & 75481 & $\begin{array}{l}\text { REBOCO ARGAMASSA TRACO } \\
\text { 1:2 (CAL E AREIA FINA } \\
\text { PENEIRADA), ESPESSURA } \\
\text { 0,5CM, PREPARO MANUAL DA } \\
\text { ARGAMASSA }\end{array}$ & $\mathrm{M}^{2}$ & & & & \\
\hline & & $\begin{array}{l}\text { ARGAMASSA TRACO 1:2 (CAL } \\
\text { E AREIA FINA PENEIRADA), } \\
\text { PREPARO MANUAL }\end{array}$ & $\mathrm{M}^{3}$ & 0,01 & $\mathrm{R} \$ 451,22$ & $\mathrm{R} \$ 2,26$ & \\
\hline & & $\begin{array}{l}\text { SERVENTE COM ENCARGOS } \\
\text { COMPLEMENTARES }\end{array}$ & $\mathrm{H}$ & 0,33 & $\mathrm{R} \$ 13,46$ & $\mathrm{R} \$ 4,44$ & \\
\hline & & $\begin{array}{l}\text { PEDREIRO COM ENCARGOS } \\
\text { COMPLEMENTARES }\end{array}$ & $\mathrm{H}$ & 0,5 & $\mathrm{R} \$ 17,39$ & $\mathrm{R} \$ 8,70$ & \\
\hline & & & & & & & $\mathrm{R} \$ 15,39$ \\
\hline \multirow[t]{4}{*}{ SINAPI } & 88495 & $\begin{array}{l}\text { APLICAÇÃO E LIXAMENTO DE } \\
\text { MASSA LÁTEX EM PAREDES, } \\
\text { UMA DEMÃO }\end{array}$ & $\mathrm{M}^{2}$ & & & & \\
\hline & & $\begin{array}{l}\text { PINTOR COM ENCARGOS } \\
\text { COMPLEMENTARES }\end{array}$ & $\mathrm{H}$ & 0,23 & $\mathrm{R} \$ 17,39$ & $\mathrm{R} \$ 4,07$ & \\
\hline & & $\begin{array}{l}\text { SERVENTE COM ENCARGOS } \\
\text { COMPLEMENTARES }\end{array}$ & $\mathrm{H}$ & 0,1 & $\mathrm{R} \$ 11,97$ & $\mathrm{R} \$ 1,03$ & \\
\hline & & VERMELHA & UNID & 0,06 & $\mathrm{R} \$ 0,74$ & $\mathrm{R} \$ 0,04$ & \\
\hline
\end{tabular}




\begin{tabular}{|c|c|c|c|c|c|c|c|}
\hline \multicolumn{8}{|c|}{ COMPOSIÇÂO UNITÁRIA PARA RESTAURAÇĀO DO SISTEMA DE REVESTIMENTOS ARGAMASSADOS } \\
\hline Fonte & Código & Descrição & Unid. & Índice & $\begin{array}{c}\text { Preço } \\
\text { Unitário }\end{array}$ & Custo & $\begin{array}{c}\text { SUB- } \\
\text { TOTAL }\end{array}$ \\
\hline & & $\begin{array}{l}\text { MASSA CORRIDA PVA PARA } \\
\text { PAREDES INTERNAS }\end{array}$ & $\mathrm{L}$ & 0,03 & $\mathrm{R} \$ 85,20$ & $\mathrm{R} \$ 2,79$ & \\
\hline & & & & & & & R\$ 7,94 \\
\hline \multirow[t]{6}{*}{ SINAPI } & 73415 & PINTURA PVA, DUAS DEMAOS & $M^{2}$ & & & & \\
\hline & & $\begin{array}{l}\text { PINTOR COM ENCARGOS } \\
\text { COMPLEMENTARES }\end{array}$ & $\mathrm{H}$ & 0,4 & $\mathrm{R} \$ 17,39$ & $\mathrm{R} \$ 6,96$ & \\
\hline & & $\begin{array}{l}\text { SERVENTE COM ENCARGOS } \\
\text { COMPLEMENTARES }\end{array}$ & $\mathrm{H}$ & 0,3 & $\mathrm{R} \$ 11,97$ & $\mathrm{R} \$ 3,59$ & \\
\hline & & $\begin{array}{l}\text { LIXA EM FOLHA PARA PAREDE } \\
\text { OU MADEIRA, NUMERO } 120 \\
\text { (COR VERMELHA) }\end{array}$ & UNID & 0,25 & $\mathrm{R} \$ 0,74$ & $\mathrm{R} \$ 0,19$ & \\
\hline & & $\begin{array}{l}\text { TINTA LATEX PVA PREMIUM, } \\
\text { COR BRANCA }\end{array}$ & $\mathrm{L}$ & 0,24 & $\mathrm{R} \$ 13,89$ & $\mathrm{R} \$ 3,33$ & \\
\hline & & & & & & & $\mathrm{R} \$ \mathbf{1 4 , 0 7}$ \\
\hline
\end{tabular}

Fonte: Elaborado pelos autores.

Em seguida, foram estimadas as áreas de todos os ambientes internos que iriam ser contemplados com os serviços propostos, descontando as áreas das esquadrias e banheiro (executado em revestimento cerâmico). Após o levantamento das áreas e com os índices averiguados na composição de custos, calculou-se o orçamento (QUADRO 6), necessário para a recomposição de uma unidade habitacional.

Quadro 6 - Orçamento da recomposição dos revestimentos argamassados internos para uma unidade habitacional

\begin{tabular}{|c|c|c|c|c|c|c|}
\hline \multicolumn{7}{|c|}{ Restauraçáo e Tratamento de cobertura } \\
\hline Fonte & Código & Descrição do Serviço & Unid. & Quant. & $\begin{array}{c}\text { Preço } \\
\text { Unitário }\end{array}$ & Custo \\
\hline SINAPI & 72125 & REMOÇÃO DE PINTURA PVA/ACRILICA & $\mathrm{M}^{2}$ & 125,85 & $\mathrm{R} \$ 6,36$ & $\mathrm{R} \$ 800,41$ \\
\hline SINAPI & 87868 & $\begin{array}{l}\text { CHAPISCO APLICADO SOMENTE EM } \\
\text { ESTRUTURAS DE CONCRETO EM ALVE- } \\
\text { NARIAS INTERNAS , COM COLHER DE } \\
\text { PEDREIRO. ARGAMASSA TRAÇO 1:3 COM } \\
\text { PREPARO MANUAL. }\end{array}$ & $M^{2}$ & 125,85 & $\mathrm{R} \$ 3,25$ & $\mathrm{R} \$ 409,01$ \\
\hline SINAPI & 87368 & $\begin{array}{l}\text { ARGAMASSA TRAÇO 1:1,5:7,5 (CIMENTO, } \\
\text { CAL E AREIA MÉDIA) PARA EMBOÇO/MAS- } \\
\text { SA ÚNICA/ASSENTAMENTO DE ALVENARIA } \\
\text { DE VEDAÇÃO, PREPARO MANUAL. }\end{array}$ & $M^{3}$ & 2,65 & $\mathrm{R} \$ 360,34$ & $\mathrm{R} \$ 954,90$ \\
\hline SINAPI & 75481 & $\begin{array}{l}\text { REBOCO ARGAMASSA TRACO 1:2 (CAL } \\
\text { E AREIA FINA PENEIRADA), ESPESSURA } \\
0,5 C M, \text { PREPARO MANUAL DA ARGAMASSA }\end{array}$ & $M^{2}$ & 125,85 & $\mathrm{R} \$ 15,39$ & $\mathrm{R} \$ 1.936,83$ \\
\hline SINAPI & 88495 & $\begin{array}{l}\text { APLICAÇÃO E LIXAMENTO DE MASSA LÁ- } \\
\text { TEX EM PAREDES, UMA DEMÃO }\end{array}$ & $M^{2}$ & 125,85 & $\mathrm{R} \$ 7,94$ & $\mathrm{R} \$ 999,25$ \\
\hline SINAPI & 73415 & PINTURA PVA, DUAS DEMAOS & $M^{2}$ & 125,85 & $\mathrm{R} \$ 14,07$ & $\mathrm{R} \$ 1.770,71$ \\
\hline \multicolumn{3}{|r|}{ TOTAL DO ORÇAMENTO } & & & & R\$ 6.871,11 \\
\hline
\end{tabular}

Fonte: Elaborado pelos autores 
Desta forma, para corrigir, apenas, os problemas levantados nos revestimentos argamassados internos, o proprietário de uma unidade habitacional terá que investir um total de R \$ 6.871,11. Comparando com o salário mínimo brasileiro, que atualmente é R \$ 937,00, o custo estimado equivale a quase 7,5 salários.

\subsection{Piso cerâmico do banheiro}

Em relação aos pisos cerâmicos, observou-se os seguintes problemas nas unidades habitacionais vistoriadas: ausência de um elemento separador entre as áreas seca e molhada do banheiro (FIGURA 7); caimento incorreto do piso cerâmico e falta de rejunte entre as cerâmicas. A combinação dos dois fatores gerava acúmulo de água no banheiro e, em alguns casos, inclusive no corredor da residência. Tal cenário, pode ocasionar várias manifestaçóes patológicas futuras, como infiltraçóes (tanto no banheiro quanto no corredor), desgaste da porta, além do desconforto gerado ao proprietário que precisa retirar o excesso de água com rodo toda vez que toma banho.

Figura 7 - Registro fotográfico do piso do banheiro das unidades habitacionais

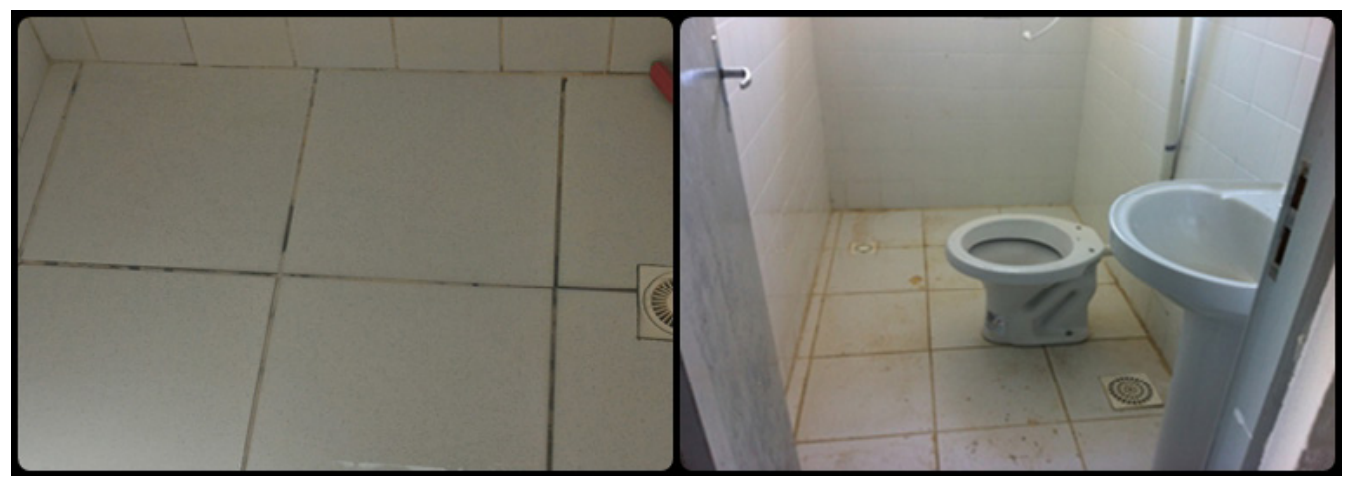

Fonte - Elaborado pelos autores

Considerando os problemas encontrados, levantaram-se junto ao SINAPI e IOPES os serviços que seriam necessários para corrigi-los. Assim os serviços encontrados foram: retirada da folha da porta, retirada os aparelhos sanitários, colocação de piso sobre piso e posteriormente recolocação dos aparelhos sanitários e da porta. Após o levantamento dos serviços necessário, elaborou-se a composição de custos unitários (QUADRO 7), para sua recuperação. 
Quadro 7 - Composição de custos unitário para orçamento de readequação do piso cerâmico

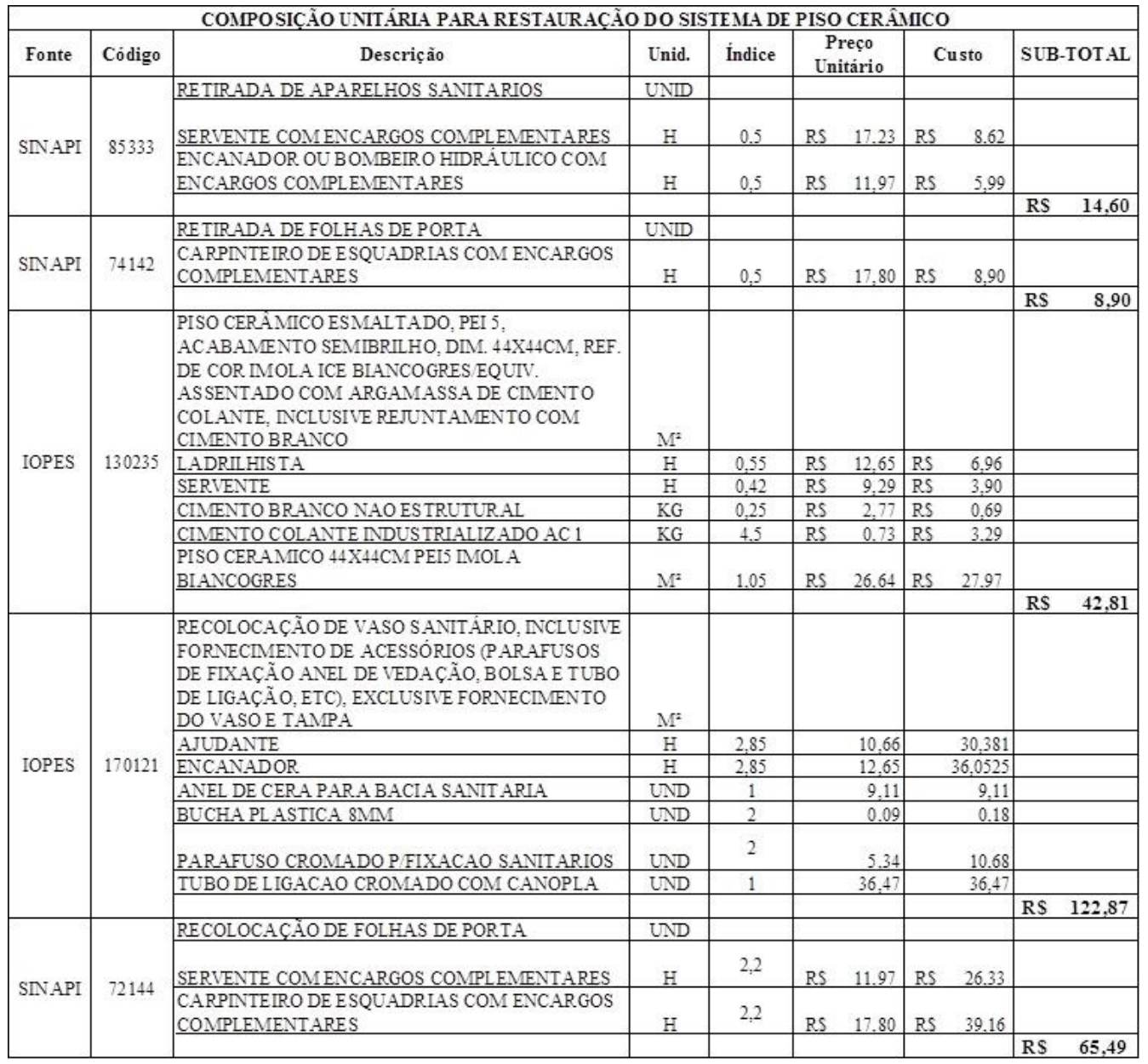

Fonte: Elaborado pelos autores.

O passo seguinte foi execução dos custos necessários para restauração de uma residência. Considerando a área do banheiro e a quantidade de elementos presentes, como: porta e sanitário. Assim, considerando os dados levantados anteriormente foi gerado o orçamento (QUADRO 8) para readequação do piso cerâmico. 
Quadro 8 - Orçamento para readequação do piso cerâmico de uma unidade habitacional

\begin{tabular}{|c|c|c|c|c|c|c|}
\hline \multicolumn{7}{|c|}{ Restauraçáo e Tratamento de piso cerâmico } \\
\hline Fonte & Código & Descriçáo do Serviço & Unid. & Quant. & \begin{tabular}{c|} 
Preço \\
Unitário
\end{tabular} & Custo \\
\hline SINAPI & 85333 & RETIRADA DE APARELHOS SANITARIOS & UND & 1 & $\mathrm{R} \$ 14,60$ & $\mathrm{R} \$ 14,60$ \\
\hline SINAPI & 72142 & RETIRADA DE FOLHAS DE PORTA & UND & 1 & $\mathrm{R} \$ 8,90$ & $\mathrm{R} \$ 8,90$ \\
\hline IOPES & $1 \mathrm{E}+05$ & $\begin{array}{l}\text { PISO CERÂMICO ESMALTADO, PEI 5, } \\
\text { ACABAMENTO SEMIBRILHO, DIM. 44X44CM, } \\
\text { REF. DE COR IMOLA ICE BIANCOGRES/EQUIV. } \\
\text { ASSENTADO COM ARGAMASSA DE CIMENTO } \\
\text { COLANTE, INCLUSIVE REJUNTAMENTO COM } \\
\text { CIMENTO BRANCO }\end{array}$ & $\mathrm{M}^{2}$ & 2,8 & $\mathrm{R} \$ 42,81$ & $\mathrm{R} \$ 119,87$ \\
\hline IOPES & $2 \mathrm{E}+05$ & $\begin{array}{l}\text { RECOLOCAÇÃO DE VASO SANITÁRIO, } \\
\text { INCLUSIVE FORNECIMENTO DE ACESSÓRIOS }\end{array}$ & UND & 1 & $\mathrm{R} \$ 122,87$ & $\mathrm{R} \$ 122,87$ \\
\hline SINAPI & 72144 & RECOLOCAÇÃO DE FOLHAS DE PORTA & UND & 1 & $\mathrm{R} \$ 65,90$ & $\mathrm{R} \$ 65,90$ \\
\hline \multicolumn{6}{|c|}{ TOTAL DO ORCAMENTO } & $\mathrm{R} \$ 332,14$ \\
\hline
\end{tabular}

Fonte: Elaborado pelos autores.

Desta forma, para readequar o piso cerâmico de uma unidade habitacional, o proprietário terá de aplicar um total de $\mathrm{R} \$ 322,14$. Apesar deste valor ser menor comparandose com os demais orçamentos realizados e apresentados no decorrer do estudo, cabe destacar que esta é uma correção necessária pois, além de gerar desconforto para os proprietários, poderá contribuir para o desenvolvimento de novas manifestaçóes patológicas.

As residências inseridas no condomínio alvo do presente estudo, foram orçadas pela Prefeitura Municipal da Serra, na Database de janeiro de 2007, sendo o custo para a construção de uma unidade habitacional completa foi de $\mathrm{R} \$ 20.110,00$. Para atualizar esse orçamento para a Database de março de 2016, foi utilizado o índice de Custo Unitário Básico (CUB), apurado pelo sindicato da indústria da construção civil no Estado do Espírito Santo (SINDUSCON-ES), que durante este período teve uma variação de 110,29\%. Assim, caso estas unidades fossem levantadas na referida Database, teriam um custo total de construção de $\mathrm{R} \$ 42.289,32$ por residência.

Considerando que o proprietário de uma unidade habitacional possua em sua residência os problemas construtivos observados e identificados nos três elementos supracitados, para sanar esses problemas o mesmo terá de desembolsar um total de $\mathrm{R} \$$ $11.720,96$, valor esse que não inclui BDI e nenhum outro tipo de despesa indireta. Ou seja, este valor de reforma representa mais de $25 \%$ do custo de construção de uma unidade completa.

Pelo programa Cartão Reforma (criado por meio da Medida Provisória 751/2016, aprovada no Congresso Nacional e que atualmente segue agora para sanção do presidente Michel Temer) famílias de baixa renda que recebem até três salários-mínimos (o equivalente a $\mathrm{R}$ \$ 2,8 mil) terão acesso ao crédito para reforma, ampliação, promoção da acessibilidade ou conclusão de obras. A previsão inicial é de que as famílias recebam crédito de $\mathrm{R} \$ 2$ mil a R\$ 9 mil para fazerem reformas de suas residências (BRASIL, 2017). Se considerar as hipóteses que o proprietário de uma unidade habitacional do condomínio deste estudo 
possua em sua residência os problemas supracitados, resolva recorrer ao programa Cartão Reforma e conseguir o valor máximo de crédito ( $\mathrm{R} \$ 9 \mathrm{mil})$, ainda assim teria que desembolsar aproximadamente $\mathrm{R} \$ 3$ mil para sanar os problemas de sua unidade habitacional.

\section{CONCLUSÃO}

Tendo em vista a oportunidade de desenvolver um estudo com o objetivo de analisar a qualidade construtiva de unidades habitacionais de cunho popular, foi analisada uma amostra de 30 (trinta) residências, com o intuito de identificar possíveis manifestaçóes patológicas. Neste sentido, foi verificado que as unidades visitadas apresentavam problemas em diversos elementos construtivos, que se manifestavam tanto de forma pontual, quanto na amostra como um todo. No estudo de caso realizado, os sistemas de cobertura, revestimento interno e piso cerâmico, são os que possuem uma maior parcela de desenvolvimento de manifestações patológicas, por isso foram abordados com maior ênfase na pesquisa.

Verificou-se que o custo para sanar apenas os problemas levantados na pesquisa, sem considerar os demais elementos construtivos que também apresentavam algum tipo de manifestação patológica ou falha, foi de $\mathrm{R} \$ 11.720,96$. Os autores tiveram acesso ao custo unitário de execução de uma residência do estudo de caso em questão. O custo desta residência, corrigido para março de 2016 (mesmo período em que foram levantados os demais custos), era de $\mathrm{R} \$ 42.289,32$. Diante dos dados supracitados, compreende-se que o custo para a reforma e readequaçáo dos elementos alvo merece atenção, uma vez que a reforma supracitada equivale mais de $25 \%$ da quantia necessária para a construção de uma unidade completa. Fazendo uma analogia com o valor do salário mínimo vigente, o custo dos serviços levantados equivale a mais de 13 salários mínimos.

Pelas moradias do estudo de caso tratarem-se de um programa popular e considerando que os proprietários das unidades vistoriadas têm como remuneração base o salário mínimo e não irão dispor de nenhum auxílio governamental para correção dos problemas, o custo levantado torna-se praticamente inviável para os proprietários, uma vez que tal valor representa, aproximadamente, a sua remuneração salarial integral durante o período de um ano.

Entende-se que todo empreendimento de construção civil está sujeito a falhas, tanto referente à projeto quanto à execução. Entretanto, os problemas e custos analisados são expressivos, visto que as manifestaçôes patológicas ocorreram com menos de um ano de entrega do empreendimento aos moradores. Diante disto, enfatiza-se a importância e necessidade de maiores estudos referentes aos projetos e a qualidade executiva de construçáo de habitaçóes populares, como forma de promover melhorias e intensificar um controle mais efetivo de qualidade como forma de minimizar os problemas relatados.

\section{REFERÊNCIAS}

ALMEIDA, R. Manifestaçóes Patológicas em Prédio Escolar: uma análise qualitativa e quantitativa. Dissertação de Mestrado, PPGEC/UFSM, 2008. 
BRASIL. Portal Brasil. Projeto do Cartão Reforma segue para sançáo presidencial. 2017. Disponível em: http://www.brasil.gov.br/infraestrutura/2017/04/projeto-do-cartaoreforma-segue-para-sancao-presidencial. Acesso em: 11 jun. 2017.

DUARTE, R. B. Fissuras em alvenarias: causas principais, medidas preventivas e técnicas de recuperação. Porto Alegre, CIENTEC (boletim técnico 25), 2008.

FRANÇA, A. A. V. et. al. Patologias das construçóes: uma especialidade da engenharia civil. Sáo Paulo, set. 2011. Disponível em: <http://techne.pini.com.br/engenhariacivil/174/patologia-das-construcoes-uma-especialidade-na-engenharia-civil-285892-1. aspx>. Acesso em: 11 jun. 2017.

FUNDAÇÃO JOÃO PINHEIROS. Déficit habitacional no Brasil. 2013. Disponível em: <http://www.fjp.mg.gov.br/index.php/produtos-e-servicos1/2742-deficithabitacional-no-brasil-3>. Acesso em: 10 mai. 2016.

GOOGLE. Google Earth. Version 2016. 2016. Balneário de Carapebus Serra-ES. Disponível em: <https://earth.google.com/web/@-20.21644211,40.21504351,13.90143677a,2642.24762496d,35y,23.87890125h,0t,0r>. Acesso em: 15 jun. 2017.

GONSALVES, E. P. Iniciação à pesquisa científica. Campinas: Alínea, 2005.

GRANDISKI, P. Olhar de perito. Revista Téchne, São Paulo, edição 87, ano 12, junho de 2004. p. 24-26

HELENE, P. R. L. A Nova NB 1/2003 (NBR 6118) e a Vida Útil das Estruturas de Concreto. Artigo Técnico. Disponível em: <http://www.phd.eng.br/wp-content/ uploads/2014/06/185.pdf>. Acesso em: 05 Ago. 2016.

HELENE, P. R. L. Manual para reparo, reforço e proteçáo de estruturas de concreto. São Paulo, Pini, 1992.

HOLZ, S.; MONTEIRO, T. V. A. Política de habitação social e o direito a moradia no Brasil. X Coloquio Internacional de Geocrítica. Disponível em: <http://www.ub.edu/ geocrit/-xcol/158.htm>. Acesso em: 11 jun. 2017.

INSTITUTO BRASILEIRO DE AVALIAÇÕES E PERÍCIAS DE ENGENHARIA. Manual do proprietário: a saúde dos edifícios, São Paulo, 1998.

INSTITUTO BRASILEIRO DE GEOGRAFIA E ESTATÍSTICA (IBGE). Renda Domiciliar Per Capita 2016. Rio de Janeiro, 2017. Disponível em: < http://www.ibge. gov.br/home/estatistica/indicadores/trabalhoerendimento/pnad_continua/default_renda_ percapita.shtm>. Acesso em: 11 jun. 2017. 
KLIMPEL, E. C.; SANTOS, P. R. C. Levantamento das manifestaçóes patológicas presentes em unidades do conjunto habitacional moradias Monteiro Lobato. Monografia (Pós Graduação em Patologias de Obras Civis). Instituto IDD, Curitiba, 2010 .

LIMA, P. R. B. Consideraçáo do projeto no desempenho dos sistemas construtivos e qualidade da edificaçáo - Proposição de um modelo de banco de dados. Dissertação UFMG. Belo Horizonte, 2005.

MIRANDA, S. S.; CORREA, C. M. B. O impacto da NBR 15575 na prática da arquitetura na cidade de Pelotas. XV Encontro de Pós Graduação UFPEL. Disponível em: <http://www2.ufpel.edu.br/enpos/2013/?sec=anais\&area=sa>. Acesso em: 06 set. 2015.

OLIVEIRA, L. A.; MITIDIERI FILHO, C. V. O projeto de edifícios habitacionais considerando a Norma Brasileira de Desempenho: análise aplicada para as vedaçóes verticais. Gestão \& Tecnologia de Projetos, [S.I.], v.7, n.1, p.90-100, mai. 20012.

PINA, G. L. Patologia nas habitaçóes populares. Monografia de Graduação em Engenharia Civil, Universidade Federal do Rio de Janeiro, 2013.

PMS. Termo de Referência dos Projetos Prioritários de Investimento para o Conjunto Habitacional de Novo Horizonte, Serra, 2009.

PUJADAS, F. Z. A. Inspeção Predial - A saúde dos edifícios. In: $1^{\circ}$ Congresso Nacional de Perícias do IBAPE. São Paulo: Agosto 2012. Disponível em: <http://ibape-nacional. com.br/biblioteca/wp-content/uploads/2012/09/INSPE\%C3_\%C3_O-PREDIALPalestra-Fl\%C3\%A1via-Pujadas.pdf >. Acesso em: 10 ago. 2016.

RIPPER, T.; MOREIRA SOUZA, V. C. Patologia, recuperaçáo e reforço de estruturas de concreto. São Paulo, Pini, 1998.

ROCHA, A. M.; KILPP, R.; KOHLER, R. Identificação de problemas patológicos e suas consequências em edificaçóes na cidade de Ijuí, RS. Rio Grande do Sul: UNIIJUI, 2006.

SPOSITO, M. E. B. O centro e as formas de expressão da centralidade urbana. Revista Geografia, São Paulo, UNESP, n. 10, p. 1-18, 1991. 